\title{
LAS POSTURAS OSCILANTES DE UNA CENTENARIA CORPORACIÓN VITIVINÍCOLA FRENTE A LA REGULACIÓN DE LA INDUSTRIA, MENDOZA, 1930-1955
}

\section{THE OSCILLATING POSTURES OF A CENTENNIAL WINE CORPORATION AGAINST THE REGULATION OF THE INDUSTRY, MENDOZA, 1930-1955}

\author{
Ana María Mateu \\ Universidad Nacional de Cuyo, Mendoza, Argentina <amateu@mendoza-conicet.gov.ar>
}

Resumen. Las regulaciones a la industria vitivinícola de Mendoza tuvieron en el periodo analizado distintos niveles de tolerancia que se expresaron en las contradicciones del discurso del Centro Vitivinícola Nacional, longeva corporación empresaria que osciló entre las preocupaciones por la rentabilidad del negocio vitivinícola y los avances sobre la libertad de mercado. Este vaivén entre políticas públicas y corporaciones empresarias es el tema de este artículo que se centra entre 1930 y 1955, año de caída del primer peronismo. Las disposiciones iniciales postergaron las mejoras en el proceso productivo y contaron con el apoyo del Centro Vitivinícola Nacional que, sin embargo, años más tarde, con corta memoria, olvidó el reclamado apoyo del Estado y se pronunció contra lo que consideró políticas totalitarias.

Palabras clave: vitivinicultura; regulación estatal; crisis; peronismo.

\begin{abstract}
In the analyzed period, the regulations to the wine industry of Mendoza had different levels of tolerance that were expressed in the contradictions of the discourse of the National Wine Centre, long-lived business corporation, which ranged among the worries for the profitability of the wine business and the advances of the free market. This game between public policies and corporate entrepreneurs is precisely the subject of this research that focuses between 1930 and 1955, year of the decline of the first Peronism. The initial regulations deferred improvements in the production process having the support of the National Wine Centre, which, however, years later, with short memory, forgot the claimed support from the State and declared against, what it considered totalitarian policies.
\end{abstract}

Key words: viticulture; state regulation; crisis; peronism.

Fecha de recepción: enero de 2013. Fecha de aceptación: mayo de 2013.

Am. Lat. Hist. Econ., año 21, núm. 1, enero-abril, 2014, pp. 134-173 


\section{INTRODUCCIÓN}

$\mathrm{L}$

as entidades gremiales constituyen un espacio privilegiado en la socialización de los intereses sectoriales, en la emergencia del conflicto, en la búsqueda y articulación del consenso y en la elaboración de políticas públicas. Enfocar la mirada en las instituciones ${ }^{1}$ y en su postura frente a los procesos de desenvolvimiento económico brinda aristas interesantes para el estudio de la vitivinicultura, que completan enfoques previos.

La historia del sector ha recibido en los últimos años una renovada atención por parte de la literatura académica que ha puesto su acento sobre los cambios agroindustriales en el largo plazo y sobre la reconversión de las últimas décadas, ${ }^{2}$ y ha aportado dentro de estos procesos perspectivas vinculadas a políticas públicas ${ }^{3}$ y actores sociales como las empresas y empresarios, ${ }^{4}$ trabajadores ${ }^{5}$ y corporaciones. ${ }^{6}$

Nutrida por estas investigaciones previas y por las nuevas perspectivas historiográficas, ${ }^{7}$ el objetivo de este trabajo es analizar la posición de la principal entidad empresaria de los bodegueros, el Centro Vitivinícola Na-

${ }^{1}$ El concepto de institución sería asimilable al de organización entendida como entidad concreta a partir de la cual los individuos se organizan y actúan en el sistema institucional dentro de una "racionalidad limitada". Lattuada, Acción, 2006, p. 49. El resurgimiento del interés por las instituciones económicas ha sido vitalizado a partir de 1990 por la perspectiva neoinstitucionalista, con sus distintas variantes en la economía, la antropología y la sociología. Este enfoque define a las organizaciones de intereses gremiales como instituciones y analiza su génesis y su desarrollo así como la influencia sobre sus asociados. Los casos de Granovetter, "Economic", 1985; Williamson, Economic, 1985, y North, Institutions, 1990, quizá son los más representativos de la idea del enraizamiento social de la economía.

${ }^{2}$ El proceso de desarrollo de la agroindustria en el largo plazo puede consultarse en Azpiazu y Basualdo, "Complejo", 2001, y Estudios, 2003; Rofman y Collado, "Impacto", 2006; Mateu, "Modelo", 2007; Richard, "Cuando", 2008, y Mateu, Vinos, 2011.

${ }^{3}$ Las políticas públicas son analizadas por, entre otros autores, Balán y López, "Burguesías", 1977; Fleming, "Cultural", 1979; Girbal-Blacha, "Ajustes", 1987; Coria y Fortín, "Boom", 1994; Mateu, "Bancos", 1994, y "Estado", 2003, pp. 177-205; Barrio, "Consolidación”, 2003; Pérez, Barrio y Sanjurjo, Región, 2006; Mateu y Stein, "Diálogos”, 2006, pp. 267-292; Barrio, Hacer, 2010, y Olguín, "Estado", 2012.

${ }^{4}$ En relación con la historia de empresas vitivinícolas, véanse Bragoni, "Redes", 1993; Mateu, "Arizu”, 1999; Bragoni, “Meritorios”, 1999, y "Estímulo", 2002; Mateu, "Aproximación”, 2002; Barrio, "Crisis", 2005; Olguín, "Políticas", 2005; Bragoni, "Familia", 2006; Mellado, "Empresariado", 2008; Olguín, "Intervención”, 2008, y Mateu, "Estudio”, 2009.

${ }^{5}$ Prieto y Choren, "Trabajo", 1990, y 1994; Salvatore, "Control", 1986; Richard, "Mercado", 2000-2001; Neiman, Bocco y Martín, "Tradicional”, 2001; Cerdá, "Trabajo", 2001; Richard, "Mercado", 2003, y Cerdá, "Mercado", 2008.

${ }^{6}$ Ospital, "Empresarios", 1995; Bunel, Schapira y Peñalva, "Empresarios", 1995; Ospital, "Intereses", 2004; McDermott, Politics, 2005; Mateu, "Vitivinicultura", 2006, y "Caminos", 2007; Bragoni et al., "Siguiendo", 2008; Mateu y Olguín, "Problema", 2008, y Olguín, "Formas", 2009; Bragoni et al., "Asociacionismo", 2011, y Mateu y Natali, "Reconversión", 2011.

${ }^{7}$ Un detallado balance sobre la renovación historiográfica en el campo de la historia económica en general y en particular sobre políticas económicas, historia regional, industria, empresas y trabajadores puede encontrarse en Gelman, Historia, 2006. 
cional (en adelante CVN), frente a la regulación de la industria en dos momentos políticos diferentes: la década de los treinta y los años del primer peronismo. Este periodo es especialmente fértil para el análisis de la acción colectiva de la corporación del vino puesto que marca los comienzos y el auge de los límites y regulaciones estatales para un modelo económico basado en la sustitución de importaciones y en el fomento del mercado interno, y en el cual la vitivinicultura ocupaba un lugar importante por su peso en la canasta familiar de los argentinos.

En 1934 el CVN apoyó las medidas de emergencia del presidente Justo, y defendió el proteccionismo ${ }^{8}$ considerando que la creación de la Junta Reguladora Nacional de Vinos y su política de extirpación de la uva eran un logro para la industria y un factor de mejora en los precios. ${ }^{9}$ Sin embargo, años más tarde, con la llegada del peronismo y con corta memoria, olvidaron el reclamado apoyo del Estado y sostuvieron que la industria se había desarrollado siempre por acción de los propios interesados y "sin intervenciones extrañas y lo que es más, siempre sin estímulos que lo reconforten o alienten", ${ }^{10}$ Reivindicaron el libre mercado, afirmando que "los hombres de negocios tienen que elegir entre una política de libre actividad económica en la que tienen la posibilidad y el derecho de ganar dinero, como lo están haciendo en este momento, y una política de tipo totalitario, en que el Estado lo regula todo, y si bien evita en algunos casos las grandes pérdidas, las más de las veces confisca o prohíbe las ganancias". ${ }^{11}$ Es por ello que se manifestaban orgullosos de ser el primer organismo gremial en haber puesto reparos al avance del gobierno sobre los derechos individuales.

Este análisis pretende demostrar que las oscilantes relaciones entre el poder político y las corporaciones y su apoyo a la intervención estatal, su reclamo, su rechazo y hasta su "olvido" pueden explicarse por la interrelación entre políticas públicas, niveles de rentabilidad de la actividad e intereses políticos, en especial luego de la llegada del peronismo al poder. ¿Cómo pueden explicarse estos vaivenes ideológicos del discurso de la corporación? ¿Cuál fue el impacto de las crisis y de las oscilaciones del mercado en la longeva corporación empresarial y en su tolerancia ante un Estado regulador que intervino sobre la oferta y luego sobre las relaciones laborales? Para este estudio utilizaremos como fuente primaria la publicación oficial del Centro Vitivinícola Nacional, ${ }^{12}$ de gran valor para

${ }^{8}$ Centro Vitivinícola Nacional, Agrícola, año XXXII, núm. 363, noviembre de 1935, pp. 152-153.

${ }^{9}$ Centro Vitivinícola Nacional, Vinos, Viñas y Frutas, año XLIV, núm. 518, noviembre de 1948, p. 219.

${ }^{10}$ Ibid., año XL, núm. 477, mayo de 1945, p. 397.

${ }^{11}$ Ibid., año XLIX, núm. 581, febrero de 1954, p. 381.

${ }^{12}$ La revista ha tenido diferentes nombres, en 1904, Boletín de la Sociedad de Defensa Vinícola Nacional; en mayo de 1908, Boletín Centro Vitivinícola Nacional; en octubre de 1917, Revista Agrícola, 
el estudio de la época, ya que recoge informes técnicos, notas de opinión y de actualidad, estadísticas y análisis comparativos, entre otros.

Para acercar algunas explicaciones nos remitiremos, en primer lugar, a esbozar algunas consideraciones sobre la agroindustria vitivinícola y sobre el gremialismo del sector.

\section{LA INDUSTRIA DEL VINO}

Mendoza tiene una larga tradición vitivinícola ${ }^{13}$ la cual, desde una raíz colonial, se transformó en una importante industria agroalimentaria orientada al mercado interno. Su crecimiento tuvo estrecha relación con la inserción del país en el circuito capitalista internacional y requirió desde fines de la década de 1870 de un Estado promotor y protector y de políticas públicas nacionales y provinciales ${ }^{14}$ que la acompañaron y facilitaron el acceso al mercado interno en expansión dinamizado por el ferrocarril.

En esos momentos fundacionales, alentar el cambio significó invertir en estudios sobre riego que cristalizaron en importantes obras de irrigación, eximir de impuestos a las nuevas plantaciones de viñas, controlar la calidad de los vinos, fomentar la inmigración, promover los créditos bancarios y hasta crear el Banco Provincia con una sección hipotecaria para la plantación de viñedos, medidas cuyo impacto relativo y desigual sobre toda la cadena ha sido analizado en anteriores trabajos

La explosión del consumo, vinculada al aumento inmigratorio, fue la fuerza motora de este crecimiento. En el periodo de 1880 a 1930 la demanda aumentó casi $5 \%$ anual, resultado por una parte del creciente número de consumidores, de origen inmigratorio, y por otra, de una duplicación en el consumo per cápita, que alcanzó 65 litros en 1915. En ese año el vino era el tercer artículo de consumo en el país después del pan y la carne, constituyendo $8.7 \%$ del gasto familiar promedio para alimentos y bebidas.

La preeminencia del mercado local se unió a la falta de una demanda y a una oferta segmentada. Muchos de los consumidores procedían de países con largas tradiciones de consumo de vino - por lo general pobres

Industrialy Comercial; el 25 de septiembre de 1920, Centro Vitivinícola Nacional, Revista Agrícola, Industrial y Comercial; el 25 de marzo de 1926, Centro Vitivinícola Nacional, Revista Mensual Ilustrada; el 25 de octubre de 1929 hasta marzo de 1935, Agrícola, Revista Mensual Ilustrada de Agricultura, Comercio e Industria; desde abril de 1940, Vinos, Viñas y Frutas, Revista Ilustrada de Enseñanza, Información y Propaganda Agrícola; en septiembre-octubre de 1945, Vinos, Viñas y Frutas, Revista Mensual Ilustrada.

${ }^{13}$ Mendoza fue, y sigue siendo, la provincia argentina de mayor importancia en términos de producción y comercio de vinos y dada su participación preeminente en la conformación del modelo, hemos decidido centrar nuestro análisis en esta región para el presente artículo.

${ }^{14}$ Sobre el tema de la protección del gobierno nacional a la producción de vinos argentinos a través de la implantación de altas tarifas aduaneras, véase Balán y López, "Burguesías", 1977. 
de origen campesino- para quienes el vino era un alimento básico. Simplemente, no demandaban un producto de calidad, sino que hubiera vino suficiente y barato $^{15} \mathrm{y}$ estos factores fueron determinantes para la estrategia del grueso de los productores. La característica común de los vinos de la época, que se prolongó durante casi todo el siglo $\mathrm{Xx}$, era los tintos no tipificados, muy ácidos, lo cual determinaba un sabor agridulce que seguiría desacreditando la industria por muchos años, aunque permitía las adulteraciones. Los vinos finos representaban sólo 5\% del total. Esto no nos debe sorprender ya que, como un reconocido técnico subrayaba en 1903, el vino bueno o regular, "obtiene el mismo precio del vino malo". Y era más rentable largar los vinos al mercado lo más rápido posible para ir reponiendo los exiguos recursos de gran parte del sector. ${ }^{16}$

El explosivo desarrollo de la industria vitivinícola o de su "resurrección", según palabras de Arata, ${ }^{17}$ se produjo dentro de una estructura productiva que marcó, con firmes contornos, el modelo, y que estaba muy concentrada en los extremos. Se conformó así un oligopsonio en las compras de uvas y un oligopolio combinado bilateral ${ }^{18}$ en el mercado de vinos. Varios años más tarde, un prestigioso industrial, perteneciente a las familias fundadoras, reconoció que la vitivinicultura en 1945 era aún una estructura inorgánica, ${ }^{19}$ fruto de la improvisación y del empirismo, con un crecimiento desordenado de los viñedos, de los vinos y de los stocks.

¿Podríamos hablar de una industria aluvial dentro de un país aluvial? Tal vez sea un buen término para describir esa primera etapa del desarrollo de un sector donde las viñas, las bodegas, los capitales, los trabajadores y los consumidores llegaron con tal rapidez y en proporciones tan grandes que los productores del vino argentino terminaron cegándose tanto a los problemas del modelo como a las posibilidades para alcanzar un progreso sustentable y a largo plazo. Las críticas de los expertos, semejantes a un "diálogo de sordos" con los industriales y el Estado, no habían logrado ningún impacto importante ni lo conseguirían por muchos años más. ${ }^{20}$

${ }^{15}$ Fernández, "Importadores”, 2008, y Mateu, "Vinos”, 2008.

${ }^{16}$ Arata, "Investigación", 1903.

${ }^{17}$ Ibid., p. 236.

${ }^{18}$ El término "combinado" hace referencia a la presencia de grandes y pequeños productores, y el término "bilateral" a la existencia de un oligopolio tanto en las ventas como en las compras de vinos. Véase Olguín, "Estado", 2012, p. 77.

${ }^{19}$ Este concepto fue sostenido por Raúl Benegas, heredero y gerente de la tradicional Bodega Trapiche, véase Centro Vitivinícola Nacional, Vinos, Viñas y Frutas, año XL, núm. 477, mayo de 1945 , p. 397.

${ }_{20}$ Mateu y Stein, "Diálogos", 2006, pp. 267-292. A partir de 1990 comenzó un proceso de reconversión productiva, véase Mateu, Vinos, 2011. 


\section{EL CENTRO VITIVINÍCOLA NACIONAL}

El empresariado no es, por lo general, un actor social homogéneo y que mantiene similares relaciones con el Estado. Su estabilidad es lábil y construye su homogeneidad colectiva a través de su comportamiento en relación con los contextos políticos y económicos y respecto a otras entidades, así como frente a las amenazas que perciba hacia sus intereses. Es precisamente en este proceso cuando se construye la "homogeneidad construida" y la acción colectiva. ${ }^{21}$ ¿Cómo se produjo este fenómeno en la agroindustria mendocina?

La tradición gremial empresaria en la industria provincial es de larga data y surgió con los primeros desequilibrios a principios del siglo Xx. Los sectores más concentrados, así como los pequeños y medianos productores de la vid y el vino se unieron para defender la posición relativa de cada uno de ellos en el conjunto de la cadena. Las primeras asociaciones que cobraron vigor estuvieron vinculadas a las crisis coyunturales y se concentraron en torno a algunos actores. Pasarían muchos años para que dentro de un nuevo contexto se intentaran soluciones integrales y alianzas estratégicas. ${ }^{22}$

Pese a tratarse de actores sociales, económicos e -incluso- políticos, de especial relevancia, los estudios sobre corporaciones empresarias y sus relaciones entre ellos y con el Estado estuvieron ausentes en las ciencias sociales argentinas hasta la década del ochenta, momento que ofició como una suerte de punto de partida para un significativo número de investigaciones en diversos periodos de la historia argentina. ${ }^{23}$

En relación con la bibliografía existente sobre las corporaciones nacionales, el gremialismo empresario vitivinícola ha sido menos estudiado, aunque debemos destacar los antecedentes referidos a la Compañía Vitivinícola de Mendoza y a las instituciones cooperativas. ${ }^{24}$ Investigadores extranjeros han prestado atención a este tema, como el artículo de Bunel y Schapira sobre el comportamiento de los empresarios mendocinos en la década de $1990^{25}$ y el de Gerald McDermott, ${ }^{26}$ que en 2005 analizó la conformación

${ }^{21}$ Para el debate sobre la construcción de intereses comunes, véanse Acuña “¿Racionalidad?”, 1997; Acuña y Golbert, "Empresarios”, 1990; Lattuada, Acción, 2006, y Lissin, "Acción”, 2008.

${ }_{22}$ Mateu y Natali, "Reconversión", 2011.

${ }^{23}$ Dentro de esta serie de estudios, podemos mencionar a Schvarzer e Itzcovitz, Organizaciones, 1986; Itzcovitz, "Organizaciones”, 1987; Sidicaro, Bolsa, 1988, y Schvarzer, Empresarios, 1991. Posteriormente, destacamos los trabajos realizados por Nun y Lattuada, Gobierno, 1991; Sidicaro, Tres, 2002; Heredia, "Reformas", 2003, y Olivera, Cooperativismo, 2006; Dossi, "Acción", 2007, y Beltrán, "Acción", 2007, p. 83. Sobre la vinculación entre agroindustrias y el gremialismo empresario, un antecedente importante lo constituye el trabajo reciente de Lattuada, Acción, 2006, y Ramírez, Corporaciones, 2007.

${ }^{24}$ Mateu, "Vitivinicultura", 2006, y "Caminos", 2007.

${ }^{25}$ Bunel, Schapira y Peñalva, "Empresarios”, 1995, pp. 227-240.

${ }^{26}$ Mc Dermott, Politics, 2005. 
de la Corporación Vitivinícola Argentina (COVIAR), como un dato significativo en relación con el disciplinamiento corporativo y con las modificaciones estructurales del sector. Recientemente, un análisis de largo plazo con base en las entidades y la rotación de sus miembros, realizado sobre fuentes y material inédito, reconstruyó trayectorias, cambios y permanencias de los elencos corporativos ${ }^{27}$ y sirvió de base para estudios posteriores.

Completando las visiones de algunos estudios anteriores ${ }^{28}$ podemos afirmar que en el caso del $\mathrm{CVN},{ }^{29}$ su creación estuvo estrechamente vinculada a fines reivindicativos y a la construcción de intereses comunes frente a la primera gran crisis de la industria de principios del siglo XX. Esta fue la primera oportunidad en la que el futuro de la actividad se tiñó de grises y esta situación se vinculó directamente con el surgimiento de la entidad. ${ }^{30}$ En 1902 la pérdida de las cosechas del litoral afectó la circulación de la moneda nacional, impactó sobre el poder adquisitivo y disminuyó el consumo. Los precios de la uva y del vino cayeron abruptamente, ${ }^{31}$ situación a la que se le unió el alto nivel de adulteración. El impacto de la crisis no fue el mismo para todos; los grandes productores responsabilizaron a los pequeños bodegueros por haber inundado el mercado y bajado los precios. Aquellos bodegueros que ya tenían armados sus circuitos de comercialización fueron los menos perjudicados, así como los que no tenían problemas de endeudamiento bancario. En general, a pesar de esta coyuntura, el número de bodegas creció y la producción y la distribución de vino aumentó.

Luego de la experiencia de algunas entidades previas, ${ }^{32}$ la estrategia que llevó al éxito al CVN fue la de integrar a los comerciantes de vino. Fue así que lograron una importante capacidad de lobby y constituirse en un actor importante, el de "mayor abolengo", ${ }^{33}$ durante más de un siglo. Sus antecedentes directos los constituye la creación, en julio de 1904, de la

${ }^{27}$ Bragoni et al., "Siguiendo", 2008, y Bragoni et al., "Asociacionismo”, 2011.

${ }^{28}$ Ospital, "Empresarios", 1995, e "Intereses", 2004; Mateu y Olguín, "Problema”, 2008, y Olguín, "Formas", 2009.

${ }^{29} \mathrm{El} \mathrm{CVN}$ no es la única entidad gremial de la época, pero ha logrado sobrevivir hasta hoy como Bodegas de Argentina e integrar la Corporación Vitivinícola Argentina. Para el periodo estudiado se crearon en 1929 la Sociedad Vitivinícola; en 1933, la Federación de Vitivinicultores, y en 1946, el Centro de Bodegueros del Este, denotando un proceso de mayor representación horizontal y vertical vinculada a sectores específicos.

${ }^{30}$ Para el análisis de esta crisis, véanse Galanti, Industria, 1900a; Arata, "Investigación", 1903, p. 236, y Barrio, "Crisis", 2008.

${ }^{31}$ Según Barrio, el precio de la uva descendió de valores que oscilaban en 1900 entre 3.30 y 4 pesos (según quien asumiera los gastos de cosecha) a 1 y 1.60 pesos en 1903 el quintal de $46 \mathrm{~kg}$. Por su parte, el precio del vino de uva francesa en Mendoza descendió de montos que variaban en 1900 entre 12 y 18 centavos el litro en bodega, a 6 centavos en 1903. Barrio, "Crisis", 2008.

${ }^{32}$ Aludimos al Centro Vitivinícola creado a fines de siglo, al Centro de Bodegueros Unidos de Mendoza de 1902 y a la Sociedad de Vitivinicultores de Mendoza de 1903.

${ }^{33}$ Centro Vitivinícola Nacional, Vinos, Viñas y Frutas, año XXXVI, núm. 420, julio de 1940. 
Sociedad Defensa Vitivinícola Nacional ${ }^{34}$ que concentró horizontalmente a los grandes bodegueros y a los principales comerciantes de vinos de Mendoza y San Juan, que vivían en Buenos Aires. ${ }^{35}$ Apenas instalados enviaron circulares para conseguir adhesión a los gobiernos provinciales, las empresas del ferrocarril y al resto de los productores, los cuales llegaron a representar más de $800000 \mathrm{hl}$ de vino, es decir, casi 60\% del total elaborado. El objetivo prioritario de esta entidad era la inspección de los vinos en los mercados consumidores para perseguir la falsificación, ${ }^{36}$ lo cual provocó reacciones entre los almaceneros y corredores de vino que en muchos casos eran los responsables del "estiramiento". Los depósitos de vino fueron los que más se resistieron a estos controles. ${ }^{37}$

En noviembre del mismo año se constituyó el Centro Vitivinícola de Mendoza, al que se suscribieron 530 bodegueros y viñateros presididos por Alfredo Ruiz. ${ }^{38}$ Por gestiones del doctor Toro Zelaya, gerente de la Sociedad Defensa Vinícola Nacional, del gobernador provincial Galigniana Segura y de Julián Barraquero, mendocino y miembro del Congreso Nacional, en marzo de 1905, las tres sociedades vitivinícolas existentes en Buenos Aires, Mendoza y San Juan, con sede principal en Buenos Aires, se concentraron en el Centro Vitivinícola Nacional. En Mendoza fue presidida por Juan Giol y tuvo delegaciones en Mendoza y San Juan, posteriormente en San Nicolás y Río Negro y circunstancialmente en Concordia. A los pocos días se dieron sus estatutos ${ }^{39}$ y comenzaron a trabajar con un subsidio de 4000 pesos mensuales que la legislatura provincial había destinado al incremento de la agricultura.

Para la celebración del centenario de la independencia, ${ }^{40}$ la corporación anunció su puesta en escena en una lujosa publicación en la que volcaron su visión sobre la industria, llena de contradicciones, y en la que mezclaban realidades y sueños. Se quejaban por la competencia de los caldos mal elaborados, pero al mismo tiempo reconocían no saber con certeza cuáles eran los mejores tipos de vino que podía proveer la industria. Aducían que las viñas mendocinas no tenían nada que envidiar a Europa,

${ }^{34}$ Sus principales miembros eran Francisco Janello (por Tomba Hnos.), Tiburcio Benegas, Alejandro Suárez, Giol y Gargantini, Balbino Arizu y Hnos., Antonio Tirasso, entre otros.

${ }_{35}$ Boletín de la Sociedad de Defensa Vinícola Nacional, año I, núm. 8, marzo de 1905, p. 102. Los miembros mendocinos eran Domingo Tomba, Juan Giol, Antonio Rafaelli, Pascual Toso y Balbino Arizu.

${ }^{36}$ En Buenos Aires, además del aguamiento de los vinos se producían importantes volúmenes de vino elaborados con pasas que eran vendidos más baratos.

${ }^{37}$ Boletín de la Sociedad de Defensa Vinícola Nacional, agosto de 1904, p. 8.

${ }^{38}$ Entre sus miembros estaban Melitón González, Ricardo Palencia, Abelardo Nanclares, Jorge Céspedes, Luis Keil y Carlos Alurralde, Juan E. Serú, Emiliano Guinazú, Arturo Jardel, Belisario Cuervo, Francisco Moyano, Pascual Arroyo, Segundo Correas, y Luis Villanueva y otros.

${ }^{39}$ Boletín de la Sociedad Vinícola Nacional, 28 de marzo de 1905, pp. 97-103.

40 Álbum del Centro Vitivinícola Nacional, La vitivinicultura, 1910. 
aunque paralelamente se lamentaban de que 75\% de la producción fuera de malbec, variedad que creían que necesitaba demasiadas correcciones en sus mostos, llegando a promocionar el tannat. Admitían que, salvo el caso de Tiburcio Benegas, quien introdujo cepas francesas, la mayoría de los bodegueros lo único que quería era producir mucho vino y venderlo pronto, sin interesarse en la calidad: "Tenían un fin, ganar dinero, hacer fortuna, sin preocuparse de la nobleza y de los medios." ${ }^{\prime 1}$ Los excesos de producción no cabían en la mente de estos empresarios, obnubilados por el aumento de la población del país y del consumo de vino por habitante. Con la convicción de que la industria sería en breve un brillante negocio, solicitaban al Estado un proteccionismo mesurado. ${ }^{42}$

\section{LOS DISCUTIDOS AÑOS TREINTA}

La crisis estructural iniciada en 1930, vinculada al crack de Wall Street del año anterior que tuvo fuertes repercusiones internacionales, se vio agudizada por el golpe de Estado de tinte nacionalista y corporativista encabezado por el general José Félix Uriburu, que derrocó al segundo gobierno radical de Hipólito Irigoyen. En el plano económico el posterior gobierno de Justo significó el fin del paradigma de crecimiento económico orientado hacia el exterior, que ya había mostrado su debilidad durante la primera guerra mundial e inauguró una etapa caracterizada por el nacionalismo económico, el proteccionismo y la economía dirigida. El Estado replanteó su participación en medio de las graves dificultades del sector agrario, cuyos precios internacionales habían caído bruscamente desde la década anterior, e impulsó como estrategia la industrialización por sustitución de importaciones, que dio como resultado la triplicación del volumen de la producción industrial entre 1935 y $1945 .{ }^{43}$

${ }^{41}$ Ibid., p. XIX.

${ }^{42}$ Ibid., p. XXVI.

${ }^{43}$ Algunas de las medidas específicas implementadas por el presidente Agustín P. Justo (1932-1938), líder de una alianza partidaria conocida como Concordancia, a quien lo sucedió Roberto Marcelino Ortiz, representante del radicalismo antipersonalista, incluyeron el control de cambios para frenar la importación; el establecimiento del Banco Central como máxima autoridad monetaria y del Instituto Movilizador de Inversiones Bancarias para asegurar la liquidez bancaria; la sanción de la Ley de Unificación de Impuestos Internos; la creación de las Juntas Reguladoras de Granos, de Vinos, de Carnes, de la Yerba Mate y del Algodón para tonificar los mercados a través del sostenimiento de los precios y del control de la producción; el fomento del crédito agrario a través del Banco Nación; la creación del Consejo Agrario Nacional (principal organismo colonizador del Estado), el bilateralismo consagrado en el Tratado Roca-Runciman sobre comercio de carnes con Inglaterra y su decidido apoyo a las inversiones británicas. Estas políticas públicas estuvieron acompañadas por un fuerte desarrollo de las migraciones internas hacia los cordones industriales, el crecimiento de la desocupación, el desmejoramiento de las condiciones 
Para esos años, la industria del vino llevaba casi 50 años de crecimiento sostenido y no planificado, de superproducción, de vaivenes de precios y de acumulación de stocks y el fracaso de algunas medidas coyunturales y reiteradas, a las cuales la helada y el granizo "resolvían" 44 como el mejor regulador. Entre las décadas de 1920 y 1930 había habido un aumento de 20000 ha en el cultivo de viñas y la producción se había duplicado y los precios de la uva y del vino sufrieron fuertes oscilaciones.

A pesar de esta situación, y con marcado optimismo, el CVN todavía veía a la industria en pleno vigor, como un "emporio de grandes riquezas y una verdadera fuente de industrialismo argentino". ${ }^{45}$ Insistían en la promoción de la calidad a través de "producir caldos baratos, de buena clase, ligeros, blancos y rosados para habituar al público al consumo" ${ }^{46}$ y reclamaban por una legislación integral sobre vinos que definiera los vinos genuinos, por un mayor apoyo crediticio para el fomento de las prácticas de añejamiento y demandaban, ya desde los primeros años de la década de 1920, por la sanción de un impuesto único al vino, ${ }^{47}$ para evitar la sobreimposición del producto que impactaba en los precios.

Durante los dos primeros años de la década, el consumo cayó de 58 a 34 litros (véase gráfica 1). Preocupada por la situación, la entidad desplegó una fuerte campaña publicitaria sobre las bondades del vino para el fomento del mercado interno, para contrarrestar la desconfianza en su calidad, la competencia de la cerveza, los altos precios y la campaña contra el alcoholismo. ${ }^{48}$ Se preocuparon también por el incentivo a la exportación, mostrando detallados análisis de los mercados de Estados Unidos, Brasil y Holanda e incluso hasta de champagne a Cuba.

En forma contemporánea, para solucionar los desequilibrios crecientes y con fines regulatorios, se había creado la Sociedad Vitivinícola, cuyo

de vida de los sectores populares y una sensible caída de la capacidad adquisitiva del mercado interno, al que, sin embargo, se trataba de fomentar. Ferro, Efectos, 2008.

${ }^{44}$ Las heladas de 1927 y de 1931 impactaron sensiblemente sobre la oferta.

${ }^{45}$ Centro Vitivinícola Nacional, Revista Mensual Ilustrada, 1927, p. s. p.

${ }^{46}$ Centro Vitivinícola Nacional, Agrícola, 1931, s. p. Trascribe la opinión del ingeniero J. Vidal (director de la Escuela de Fruticultura de Dolores).

${ }^{47}$ Esta prédica culminará con la sanción de la Ley Nacional 12.139 sobre la unificación de los impuestos internos, viejo anhelo de la entidad y que absorbía la imposición al consumo de las provincias, lo cual impactaba sobre el federalismo. El Banco Nación haría el reparto de los fondos. Por esta ley los vinos genuinos de producción nacional o importados pagarían como impuesto interno por litro, la tasa de 0.05 pesos m. n. (art. 25).

${ }^{48}$ Es muy interesante analizar la propaganda del CVN, que incluye desde la receta para hacer un buen clericot, hasta promocionar que un vaso de vino tiene los mismos beneficios que ingerir cuatro huevos, junto a las citas científicas de Luis Pasteur. En 1931 criticó que una de las bodegas más acreditadas de Mendoza decidiera sortear autos y máquinas de coser para aumentar el consumo de sus vinos sin atender a la promoción de la calidad. En 1934 se aconsejaba cómo se deben vender los vinos en los restaurantes y hoteles, a buen precio, perfecta calidad y auténticos. 
GRÁFICA 1. CONSUMO PER CÁPITA NACIONAL (LITROS), 1928-1955

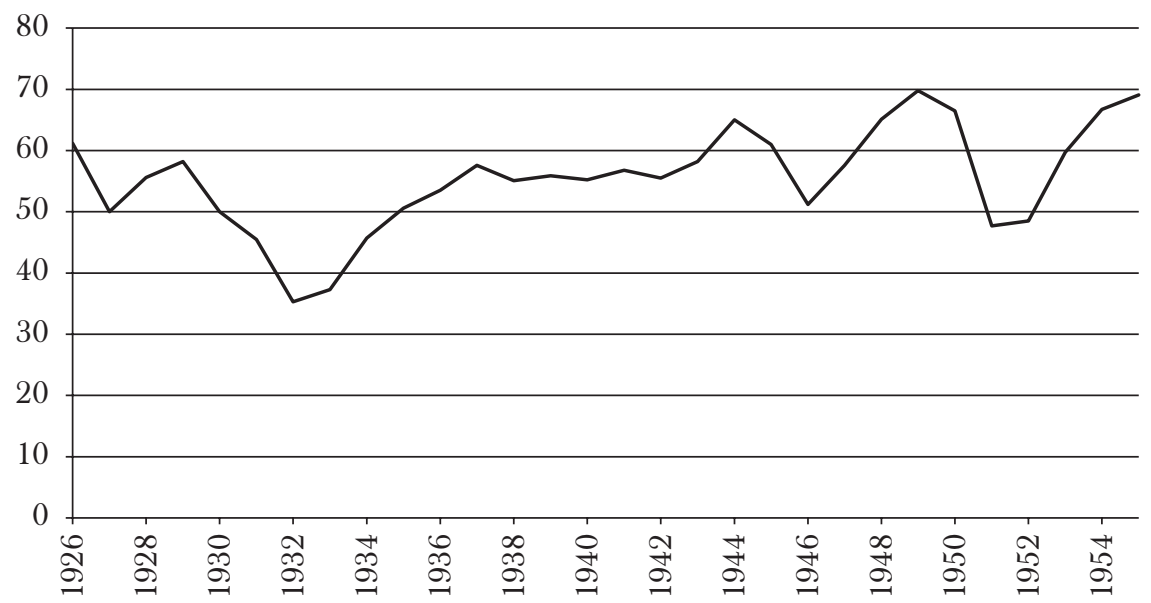

—Consumo per cápita nacional (litros)

Fuente: Anuario, años 1952, 1955 y 1956.

mentor había sido Alejandro Bunge. ${ }^{49}$ Se trataba de una sociedad anónima integrada por bodegueros y viñateros que debía fijar el precio de la uva y del vino, manejar la comercialización y comprar $60 \%$ de la producción de vino para retirarla del mercado. El CVN se opuso férreamente al plan Bunge porque no tenía nada de novedoso y porque no planteaba soluciones de fondo.

En 1932 nuevamente el espejismo de las heladas hizo creer que el mercado estaba saneado, lo que llevó a que gran parte de los bodegueros rescindiera los contratos con la Sociedad Vitivinícola motivando su liquidación, situación que se produjo también en San Juan. Pero la situación se complicó nuevamente al año siguiente, momento en que el gobernador de Mendoza, Ricardo Videla, del tradicional Partido Demócrata Nacional, ex Partido Conservador, estableció el precio para el levantamiento de la cose-

${ }^{49}$ Bunge, un intelectual propulsor de la industrialización, proveniente del liberalismo católico, elaboró un detallado diagnóstico a pedido de la Sociedad de Defensa Vitivinícola y propuso la creación de la Sociedad Vitivinícola que debería integrar a las dos terceras partes de los productores de Mendoza y San Juan. Propuso nuevas maneras de financiamiento a la industria que no fueron del agrado de los bancos y fue disuelta. Para un detallado estudio, véanse Lucchini, Blanco y Cerra, "Pensamiento", 2000; Pantaleón, "Surgimiento", 2004, pp. 175-201, y Olguín y Mellado, "Crisis", 2006. 
cha de $1934,{ }^{50}$ a través de la recientemente creada Comisión Autónoma de Defensa Vitivinícola. ${ }^{51}$ Queremos remarcar que, a nuestro juicio, los propósitos de esta entidad superaron las intenciones meramente regulatorias ya que apuntaron a la mejora de la calidad y a la ampliación del mercado de consumo. Para lograr un producto diferenciado y de mayor calidad dentro de la oferta de la época, creó una nueva variedad, los "vinos típicos superiores", que deberían tener una guarda no inferior a los tres años y determinar su zona de producción, cepaje y sistema de elaboración y mantener caracteres organolépticos constantes. Por otra parte, la comisión fomentó la ampliación del mercado interno a través del otorgamiento de una prima a quienes vendieran vinos en los territorios nacionales donde el consumo per cápita fuera inferior a 25 litros al año, a los que exportaran al extranjero y a los que vendieran en el interior o en el extranjero vinos típicos superiores embotellados.

Las últimas leyes de $1933^{52}$ otorgaron facilidades para la construcción de bodegas regionales, para el establecimiento de cooperativas privadas o asociadas al Estado, establecieron normas sobre fraccionamiento en origen $^{53}$ (en botellas de vidrio cerradas herméticas, de una capacidad no mayor de 1000 centímetros cúbicos y con una estampilla en donde constara el pago del impuesto), dispusieron normativas para los vinos típicos superiores, eximieron de impuestos a las cooperativas que elaboraran, compraran, formaran reserva y expendieran vinos fuera de la provincia, derogaron impuestos que gravaban la circulación del consumo de vino en el país y otorgaron el carácter de oficial a la primera sociedad cooperativa de venta directa de vino al consumidor que se formase (con un número no menor de 50 asociados), con derecho de uso del nombre y emblemas de la provincia en sus locales de venta o agencias oficiales y en las marcas y envases de productos. Pero, estas medidas, muchas de ellas novedosas ya que apuntan a lograr una mayor calidad y un aumento del consumo, quedaron únicamente como una aspiración de deseos en medio de la caída de los precios y de la demanda.

${ }^{50}$ Anales de Legislación Argentina. Repertorio, Ley núm. 1067, Mendoza, 6 de diciembre de 1933.

${ }^{51}$ Ibid., Ley núm. 1068, Mendoza, 6 de diciembre de 1933.

${ }^{52}$ Ibid., Ley núm. 1071, del 6 de diciembre de 1933; Ley núm. 1072, del 4 de diciembre de 1933; Ley núm. 1073, del 4 de diciembre de 1933, y Ley núm. 1078, del 28 de diciembre de 1933.

${ }^{53}$ La Ley sobre fraccionamiento en origen (núm. 23149) se consiguió recién en 1984 y determinó que "el fraccionamiento de vinos en envases menores de 930 centímetros cúbicos y mayores de 1500 centímetros cúbicos deberá realizarse exclusivamente en las zonas de origen de producción de las uvas". El artículo segundo estableció que "se considera zona de origen aquella donde se produce la uva utilizada para elaboración del vino, de acuerdo con las normas por el Instituto Nacional de Vitivinicultura y la Ley general de vinos". 
En 1934, ni la intención de compra por parte del ejecutivo ${ }^{54}$ de 2000000 de quintales de uva de la vendimia a los sectores más vulnerables (viñateros sin bodega, bodegueros sin capacidad de vasija, contratistas y medieros), ni la proyectada adquisición ${ }^{55}$ de toda la uva vinificable de la cosecha del año 1935 para constituir una reserva de 750000 cascos de vino, lograron aquietar el panorama. Al contrario, a fines de año, la situación de la industria vitivinícola seguía empeorando, el consumo continuaba en baja y los precios habían descendido verticalmente al punto que no alcanzaban a cubrir los costos.

En el contexto de medidas que no cristalizaban y de la grave situación que acabamos de esbozar, el ejecutivo nacional intervino en la regulación, como lo estaba haciendo con otras producciones regionales. ${ }^{56} \mathrm{El}$ propio presidente Justo, en el mensaje al Congreso que antecedió a la ley de creación de la Junta Reguladora de Vinos, reconoció su temor de emprender una ruta intervencionista sosteniendo que se trataba de una situación de "miseria ocasionada por la abundancia". 57

En realidad, las regulaciones habían estado presentes en la historia del $\operatorname{sector}^{58}$ a partir de las dos primeras crisis del sector en el siglo XX. La mayoría de las medidas ya habían sido ensayadas: comisiones oficiales ${ }^{59}$ y privadas para el análisis de la situación y aplicación de regulaciones; fomento del cooperativismo; ${ }^{60}$ construcción de bodegas regionales ${ }^{61}$ y hasta la eliminación de uvas y vinos ${ }^{62}$ para equilibrar la producción (véanse

${ }^{54}$ Anales de Legislación Argentina. Repertorio, Ley núm. 1091, Mendoza, 4 de abril de 1934.

${ }^{55}$ Ibid., Ley núm. 1128, Mendoza, 29 de noviembre de 1934.

${ }^{56}$ La decisión debe enmarcarse en la política económica instrumentada por Pinedo como ministro de Hacienda de Justo y sus ideas intervencionistas sobre el Estado y su objetivo de que no decayera la producción y el consumo en las actividades más importantes.

${ }^{57}$ Palabras utilizadas por el presidente Justo en el mensaje que antecede a la Ley 12.137 del 24 de diciembre de 1934. Junta Reguladora de Vinos, Recopilación, 1941, p. 30. Para un estudio detallado de este periodo, véase Mateu, "Vitivinicultura", 2006.

${ }^{58}$ Ospital, "Empresarios", 1995; Mateu, "Caminos", 2007; Ospital, "Intereses", 2004, "Políticas", 2005, y "Caso", 2005; Mateu y Olguín, "Problema”, 2008; Ospital, "Modernización”, 2009, y Olguín, "Formas", 2009. Para una mirada general, véase Ferro, Efectos, 2008.

${ }_{59}$ Anales de Legislación Argentina. Repertorio, Ley núm. 55, Mendoza, 6 de octubre de 1897. Creación de la Comisión de Defensa de la Industria Vitivinícola, Ley núm. 625, Mendoza, 1 de mayo de 1914; Creación de la Comisión de Defensa y Fomento Industrial, Ley núm. 703, Mendoza, 1 de diciembre de 1916; Creación de la Compañía Vitivinícola, Ley núm. 1068, Mendoza, 6 de diciembre de 1933; Creación de la Comisión Autónoma de Defensa Vitivinícola.

${ }^{60} \mathrm{Ibid}$., Ley núm. 703, Mendoza; Ley núm. 759, Mendoza, 1919; Ley núm. 1073, Mendoza, 4 de diciembre de 1933, eximiendo de impuestos a las cooperativas.

${ }^{61}$ Ibid., Ley núm. 758, Mendoza, 6 de noviembre de 1919; Ley núm. 1071, Mendoza, 6 de diciembre de 1933, Sobre construcciones de bodegas regionales.

${ }^{62}$ La eliminación se produjo en los años 1915 y 1916 de acuerdo con lo decidido por la Comisión de Fomento Industrial y en 1918 y 1919 por la actuación de la Compañía Vitivinícola. 
gráficas 2 y 3). Sin embargo, la industria era continuamente gravada según su productividad (por hectolitro, litro o quintal), ${ }^{63}$ demostrando que el Estado era el mayor beneficiario de este tipo de modelo. ${ }^{64}$

$\mathrm{El}$ análisis del debate legislativo ante la aprobación de ambas leyes regulatorias ilumina aspectos poco conocidos del funcionamiento de las relaciones políticas y económicas en torno al sector vitivinícola, así como de las maneras diferentes de percibir la crisis. En primer lugar, debemos señalar el desempeño acotado del bloque conservador mendocino, que se limitó a insistir en demostrar la sobreproducción a través de una profusión de datos, cuya exactitud fue discutida por la oposición. Los senadores Rodolfo Corominas Segura y Gilberto Suárez Lago, y los diputados Adolfo Vicchi y Raúl Godoy, exhibieron una visión inocente sobre la crisis al desvincularla del accionar de los gobiernos mendocinos y de sus consecuencias sobre la agroindustria. No discutieron las implicancias del modelo ni, menos aún, un posible agotamiento del mismo o la llegada a un límite de su desarrollo. Se apoyaron en algunos estudios técnicos, los mismos utilizados por el Estado nacional, uno de ellos de un asesor industrial del Banco Nación, Héctor Liaudat -también funcionario del Banco Nación de la Oficina de Investigaciones Económicas-, y en el asesoramiento del economista conservador Raúl Prebisch, presidente del Banco Central.

Sobre la base de unas pocas historias particulares y descontextualizadas, exhibieron una visión idílica, despolitizada y hasta legendaria de la industria, que hasta hoy sigue formando parte de los grandes mitos sobre su crecimiento. Los principales elementos de esta postura fueron un relato acrítico, centrado en el éxito de los grandes productores e ignorante de los otros actores de la cadena, y en el que las crisis constituían solamente un fenómeno coyuntural y un traspié en medio de un crecimiento exitoso. Otro de los rasgos de esta posición fueron el no reconocimiento de relaciones asimétricas dentro de la cadena agroindustrial, así como de la presencia de monopolios y monopsonios y del poder de lobby de los grandes propietarios. En este sentido, se notó una recurrencia a la exaltación del

${ }^{63}$ La industria, en relación con las viñas, por hectárea o por planta, por quintal de uva o por litro o hectolitro de vino, fue gravada impositivamente en los años 1895, por las leyes núm. 107 de 1898, núm. 137 de 1899, núm. 183 de 1900, núm. 232 de 1901, núm. 255 y 259 de 1902, núm. 435 de 1908, núm. 584 de 1912, núm. 645 de 1914, núm. 655 de 1915, núm. 703 de 1916, núm. 903 de 1926, núm. 918 de 1927, núm. 935 de 1932, núm. 1006 de 1933, núm. 1131 de 1934 y por las leyes nacionales núm. 3469 de Impuestos Internos de 1897 y núm. 9645 de Derechos de Análisis en las Oficinas Químicas Nacionales de 1915.

${ }^{64}$ Los nuevos impuestos a la agroindustria financiaron obras de irrigación, construcción de edificios públicos (escuelas, cárceles, reformatorios, etc.), dispensarios para la lucha antivenérea en toda la provincia y préstamos de habilitación agrícola para las industrias de grano (incluida la uva), préstamos a la Dirección General de Escuelas y para el sostenimiento de la Caja Obrera de Pensión a la Vejez e Invalidez. 
GRÁFICA 2. HECTÁREAS CULTIVADAS, 1930-1954

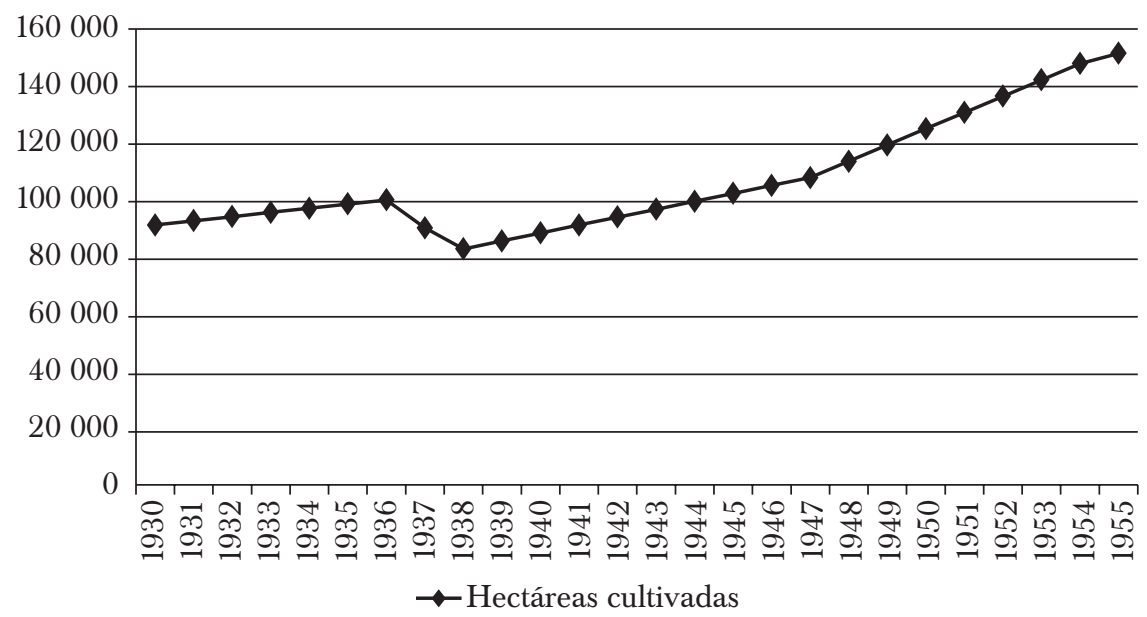

Fuente: Anuario, años 1952, 1955 y 1956.

GRÁFICA 3. EVOLUCIÓN DE LA PRODUCCIÓN DE UVA

(QUINTALES) Y DE VINO (LITROS), 1930-1954

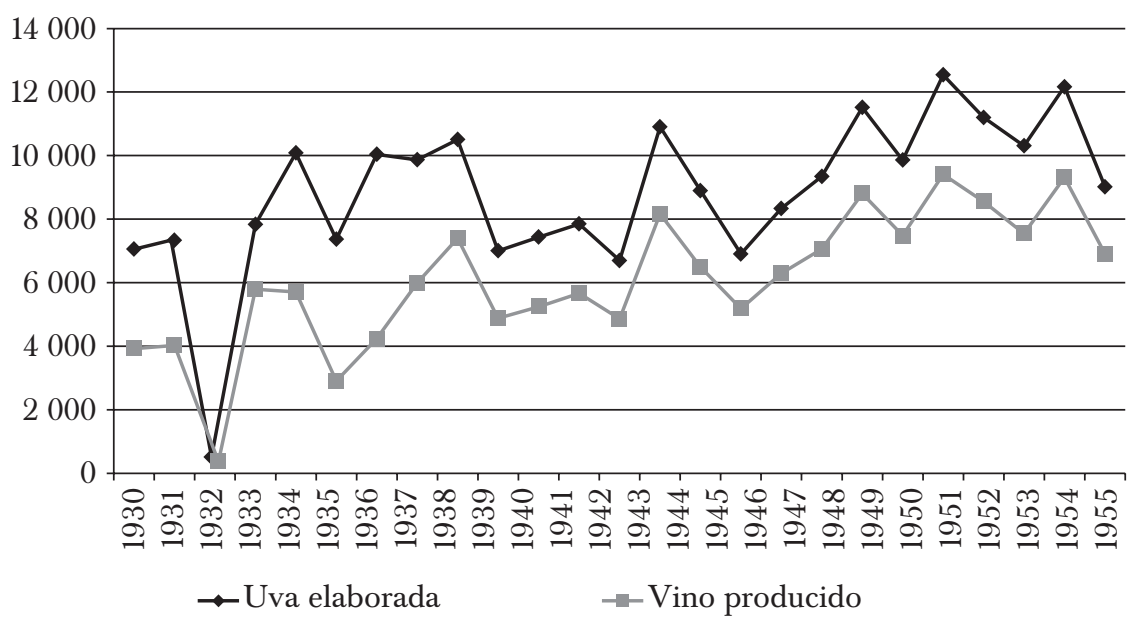

Fuente: Anuario, años 1952, 1955 y 1956. 
contratista de viña ${ }^{65}$ como muestra de una actividad con alta movilidad vertical entre sus eslabones y sin reconocer los beneficios que el sistema trajo a los propietarios. Sobre el paso de inmigrante a contratista y de contratista a "potentado", construyeron un relato "mítico" sobre la "indiscutible" movilidad social de los años previos a la Gran Depresión. La bancada oficialista no vinculó la crisis de la industria con los problemas financieros y bancarios de la década de 1930 y soslayó la importancia del peso de la gravosa e histórica carga impositiva provincial sobre los productores, problema con el que supuestamente había terminado la sanción de la Ley de Impuestos Internos. ${ }^{6}$ Defensores del liberalismo económico, los conservadores justificaron el intervencionismo estatal sólo por razones de emergencia y remarcaron que las regulaciones del mercado no constituían una contradicción con estos principios, por tratarse de "simples correcciones" de la oferta y la demanda.

Por su parte, la bancada socialista, a través del discurso opositor de los diputados José Luis Pena, Adolfo Dickmann, Nicolás Repetto y Manuel Palacín y del senador Carlos R. Porto sí puso en tela de juicio el modelo, sus rasgos y sus desequilibrios, la participación del Estado y las incoherencias entre la regulación y la teoría económica neoclásica. Se centraron en el problema de la calidad de los vinos al señalar al aguamiento como responsable de la superproducción, aseverando que era tan común esta práctica que los comerciantes hacían propaganda de sus vinos afirmando que por cada bordelesa de 200 litros se les podía agregar cuatro damajuanas de agua. Llegaron a decir que era una industria basada fundamentalmente en la química y no en las uvas. Se mostraron disconformes con que hubiera que invertir dineros públicos para que los cinco grandes industriales mendocinos (Giol, Arizu, Tomba, Tirasso y Escorihuela) siguieran siendo millonarios, afirmando "lo poco que el país debe a esos pretendidos promotores de la industria cuyana, cuyas bodegas, las más grandes del mundo, no tienen otro origen que la explotación, del transportador, del banco, del obrero y de la salud del consumidor" ${ }^{67}$ Aseguraban que esas

${ }^{65}$ La figura del contratista fue muy importante en la difusión de los cultivos en el espacio irrigado y remite al encargado de mantener en óptimas condiciones de producción una viña, a cambio de lo cual recibía una parte de la producción y un salario. Este importante actor agrícola asumió distintas características y estuvo unido a los propietarios por una gran variedad de relaciones contractuales. Sobre ellos, en especial sobre el contratista de plantación, se hace recaer parte de la responsabilidad del modelo productivista y sin calidad, ya que cobraba por cepa implantada y se quedaba con algunas cosechas. Si bien algunos fueron una mezcla de trabajadores y empresarios y acumularon capital suficiente para convertirse en viñateros, no puede desconocerse que el sistema también beneficiaba al propietario rentista y ausente, quien recibía la tierra en plena productividad y se asociaba en los riesgos de granizo y helada. Véase Richard, "Mercado", 2003.

${ }^{66}$ En este sentido, el CVN llevará desde 1904, año de su creación, una fuerte campaña para la rebaja de la carga impositiva.

${ }^{67}$ Diario de sesiones, Cámara de Diputados, 5 de diciembre de 1934, p. 634. 
cinco bodegas eran establecimientos con un desarrollo monstruoso y que llevaban a la conformación de un estado provincial patológico debido a la alta concentración del poder económico. ${ }^{68}$ Centraron también su crítica en la situación de los bancos, que al borde de la quiebra, presionaban ante el gobierno para que solucionara el problema de los productores. ${ }^{69}$

Cuando todo estuvo dicho, las leyes que crearon y reglamentaron la Junta lograron escasamente los votos necesarios para ser sancionadas, terminando la sesión con las palabras del diputado socialista Enrique Dickman, declarando que se trataba de "una brutal ley reguladora, tan audaz que no se animarían ni los bolcheviques". ${ }^{70}$

Para la Navidad de 1934 se sancionó la Ley nacional núm. 12137 de creación de la Junta Reguladora de Vinos, "con carácter de emergencia" para regularizar la producción y el consumo ${ }^{71}$ a través de distintas medidas: eliminación de vitis vinífera o su sustitución por uva de mesa o de pasas o por otro cultivo previas indemnizaciones a los productores; compra de uva con destino distinto a la elaboración del vino y adquisición de los excedentes. La ley también repetía el viejo anhelo de promoción de la agrupación de los productores de uva sin bodega en entidades cooperativas para la industrialización y comercialización de sus cosechas.

Poco tiempo después, la Ley núm. 12355 fue más drástica e instrumentó la compra de 20000000 de quintales de uva (1300 000 pertenecientes a Mendoza) en zonas típicamente vitivinícolas. ${ }^{72}$ Se compraron en 1935 un total de 3084080 quintales de uva para ser eliminados, provenientes de 45648 ha, es decir, casi la mitad de la producción de Mendoza, cuyo 86\% pertenecía a los viñateros sin bodega y $50 \%$ correspondía a uva francesa, en especial malbec, proveniente en $50 \%$ de propiedades no mayores a cinco hectáreas. Al año siguiente, la operatoria se repitió para 900000 quintales más, aunque las compras estuvieron destinadas a propiedades algo más grandes y en $81 \%$ a viñateros sin bodega. No sorprende que los estudios den cuenta del alto endeudamiento de quienes vendieron sus uvas, a quienes fue a parar en 1936 sólo 10\% de los montos pagados por la

${ }^{68} \mathrm{Ibid}$.

${ }^{69}$ Con el objetivo de ordenar el sistema monetario y financiero, se creó el Banco Central de la República Argentina y el Instituto Movilizador de Inversiones Bancarias, se sancionó la Ley de Bancos y se modificaron las leyes orgánicas de los bancos oficiales.

${ }^{70}$ Diario de sesiones, Cámara de Diputados, 5 de diciembre de 1934, p. 691.

${ }^{71}$ Sus miembros serían designados por el ejecutivo, con acuerdo del Senado, y funcionarían con el asesoramiento de una comisión ad honorem, también se daría representación al Banco Nación Hipotecario y demás intereses afectados.

${ }^{72}$ Estas tierras pasarían al dominio privado de la nación, para ser divididas en lotes de hasta cinco hectáreas y vendidas a trabajadores rurales a razón de un lote por familia, con la condición de que establecieran allí su hogar y que lo cultivasen con cualquier cultivo que no fuera uva. Marianetti señala que el plan de colonización nunca se concretó y a las fincas las ganó el desierto. Marianetti, Racimo, 1965. 
Junta, mientras que el resto fue a parar a acreedores hipotecarios, embargos, cesiones y contratistas. ${ }^{73}$

En las páginas de su propia Memoria, la Junta Reguladora reconocía que la extirpación chocaba con un concepto popular, a su juicio, fundado más en el sentimentalismo que en el raciocinio y según el cual se trataba de una censurable "destrucción de la riqueza". Justificaban la eliminación en la postura de que lo que no es deseado no tiene valor: "El propietario de un viñedo marginal aguanta mientras le permitan sus reservas o los acreedores lo esperen. Terminadas las reservas y esperas se remata el inmueble, pero el viñedo sigue produciendo más o menos la misma cantidad de uva. El propietario no ha sobrevivido económicamente a la marginalidad, pero sí el viñedo causante de su ruina.. ${ }^{74} \mathrm{El}$ texto terminaba justificando que la vitalidad de los viñedos marginales era una razón de más para tratar de extirpar siquiera algunos de ellos, con el fin de que no siguieran causando un daño social al aumentar los excedentes, y otro individual, al arruinar viñatero tras viñatero. ${ }^{75}$

¿Cuál fue la postura del CVN sobre las medidas reguladoras de la década de 1930 y que motivaron el derrame del vino en las acequias mendocinas, aún presente en el imaginario colectivo? La férrea oposición a la pretendida regulación de la Sociedad Vitivinícola que había motivado hasta entrevistas con el presidente de facto Uriburu, para que no reconociera sus operaciones, fue suavizada respecto a la Junta Reguladora con la cual colaboró y asesoró, por ejemplo, en las estimaciones de las hectáreas a suprimir y en los montos a pagar por la entidad a los damnificados. Algunos miembros ${ }^{76}$ del $\mathrm{CVN}$ fueron asesores de la Junta, a la que calificaron como un logro que, junto a la ley de unificación de impuestos, permitían mirar con confianza el porvenir.

Sin embargo, luego de disolverse la Junta en 1942, y ante la recuperación del poder adquisitivo, el CVN en $1945^{77}$ sostuvo que se habían malgastado millones de pesos que fueron cargados al precio del vino al consumidor y que el aumento de consumo no había sido mérito del gobierno, ni de la Junta Reguladora ni de las sociedades vitivinícolas al eliminar las cosechas, sino que, por el contrario, las acciones desplegadas habían retardado la demanda por el incremento de los precios para afrontar la extirpación y la posterior replantación de nuevas hectáreas.

\footnotetext{
${ }^{73}$ Junta Reguladora de Vinos, Recopilación, 1941, pp. 40-43.

${ }_{74}$ Junta Reguladora de Vinos, Memoria, 1935, p. 354.

${ }^{75}$ Ibid.

${ }^{76}$ Se trató de Jorge Aubone y Benjamín Sánchez Anzorena.

${ }^{77}$ Centro Vitivinícola Nacional, Vinos, Viñas y Frutas, núm. 479, julio de 1945, p. 6.
} 


\section{LOS CONTROVERTIDOS AÑOS PERONISTAS}

Durante los años de la posguerra, el peronismo propuso políticas para alcanzar el pleno empleo y una mejora en la remuneración real de los asalariados en el marco de un incremento de la industrialización con un fuerte apoyo de la intervención del Estado. ${ }^{78}$ La redistribución del ingreso a favor de los obreros y de la pequeña y mediana industria que producían para el mercado interno, suponía una alianza entre ellas para superar la crisis de dependencia y de distribución, desnudada en la década de 1930. El gobierno estableció que el Estado orientaría los factores de la economía nacional y que el capital estaría al servicio de la economía, con el objeto de crear una economía social. ${ }^{79}$

¿Cómo se estructurarían las relaciones entre estos postulados y una entidad corporativa representante de los intereses de los bodegueros? Las acciones de regulación directa de la producción agroindustrial adoptadas por la Junta Reguladora de Vinos ${ }^{80}$ se cambiaron por otras, que afectarían en especial a la comercialización por medio del control de precios ${ }^{81}$ y a las relaciones laborales en los distintos eslabones de la cadena, medidas ambas que causaron el descontento en el seno de la entidad.

El gobierno de facto de Edelmiro Farrell, en medio del preocupante aumento de los precios, adoptó en 1944 la medida más temida por el CVN: el control de precios de los vinos como parte de una política general destinada a los bienes de consumo de primera necesidad. ${ }^{82}$ Esta intervención avanzó a medida que el problema inflacionario se tornó más incontrolable, afectando a otros eslabones de la cadena productiva, como a los bode-

${ }^{78}$ Véanse Rougier, Política, 2001; Girbal-Blacha, Estado, 2002; Gerchunof y Antúnez, "Bonanza", 2002; Gerchunoff y Llach, Ciclo, 2003; Belini, "Estado", 2004; Girbal-Blacha, Mitos, 2004; Belini, Industria, 2009; Rougier, Estudios, 2010, y Garzón, “Experiencia”, 2010.

${ }^{79}$ Girbal-Blacha, Estado, 2002, recrea las palabras del Manual del peronista, 1948.

${ }^{80}$ La Junta Reguladora fue disuelta en 1943 por el Decreto nacional núm. 1298, que creó la Dirección de Vitivinicultura.

${ }^{81}$ Un antecedente directo de la intervención en la fijación de precios lo constituye la Ley 12.591 del 9 de septiembre de 1939 que reprimía la especulación y establecía precios máximos de venta al consumidor para los artículos de primera necesidad, retrotrayéndolos a la primera quincena de agosto de 1939. Todos los productores deberían declarar las existencias que no fueran dedicadas al autoconsumo. Las medidas iban acompañadas de la prohibición de la rebaja de los sueldos y salarios bajo el pretexto de la fijación de los precios máximos. El artículo 16 declaraba de utilidad pública y sujetos a expropiación las mercaderías y los productos comprendidos en la ley y las materias primas necesarias para su elaboración. Esta medida, considerada de emergencia, no incluyó al vino en el listado de artículos de alimentación, vestidos, vivienda, materiales de construcción, alumbrado, calefacción y sanidad. En Mendoza, la Ley nacional fue complementada por la ley provincial núm. 1444 de noviembre de 1941 y por el decreto del mismo mes que creó la Comisión de Abastecimiento cuya función era proponer los precios máximos y sus modificaciones y llevar un registro de proveedores. En los considerandos tampoco se hacía alusión al vino.

${ }^{82}$ Anales de Legislación Argentina, Repertorio, Decreto nacional núm. 11.901, 30 de mayo de 1945, y Decreto nacional núm. 869 de 1932, que declara el vino como artículo de primera necesidad. 
gueros trasladistas y los viñateros. ${ }^{83}$ A partir de 1949 distintas resoluciones nacionales fueron fijando precios máximos al vino hasta 1954 .

El control de precios no sólo provocó reacciones entre la gremial bodeguera, sino en la Sociedad de Bodegueros Trasladistas, la Asociación de Viñateros y el Centro de Contratistas, sectores todos que se fueron organizando cuando vieron perjudicada su rentabilidad, aunque el gobierno no dio marcha atrás.

Pero, mientras tanto ċqué pasaba con la demanda? Desde 1945, el consumo de vino ${ }^{84}$ per cápita había aumentado por la mejora del poder adquisitivo de los salarios y a pesar de la inflación. Fue entonces que el CVN culpó a la Junta Reguladora de la falta de vinos, advirtiendo también acerca de la menor rentabilidad de los bodegueros trasladistas ${ }^{85}$ y exportadores.

Una entrevista realizada ${ }^{86}$ a un famoso enólogo mendocino ilustra sobre los problemas para satisfacer la demanda:

Un día me llama el gobernador y me dice: "Mire me va a tener que acompañar a Buenos Aires, porque me llamó la señora Eva, porque tenemos un problema serio en la Capital Federal por el asunto del vino." Nos dijo lo siguiente: "Mire, el problema que yo tengo es con la gente del Sindicato de Obreros y Empleados Vitivinícolas y Afines (SOEVA), el organismo sindical de trabajadores de bodegas. Porque en Buenos Aires el consumo de vino había aumentado considerablemente y las plantas de fraccionamiento no podían abastecer la demanda, porque no había vino disponible. Como consecuencia de las medidas que tomó la Junta Reguladora de Vinos se ha reducido enormemente la producción de vinos, ipero, caramba! -dice la señora- ¿Qué otra cosa podemos hacer?, y no hay [...] lo único que podríamos hacer es importar vino para seguir abasteciendo, pero no tenemos muchos recursos." Entonces dijo: "Bueno, vamos a hablar con los bodegueros [...] y empezamos a hablar con ellos y me dijeron que no se podía importar vino de

${ }^{83}$ Decreto nacional núm. 3.134, julio de 1946; Decreto nacional núm. 30.493, 29 de diciembre de 1948; Decreto nacional núm. 24.573, noviembre de 1949; Decreto nacional núm. 8.348, abril de 1950. Posteriormente la fijación hasta 1954 se hizo por resoluciones y disposiciones nacionales.

${ }^{84}$ Desde 1944 había comenzado a ascender, llegando a los 69.8 litros en 1949, bajando a 47.8 litros en 1951 y subiendo a 59.7 litros en 1953.

${ }^{85} \mathrm{El}$ aumento del precio del vino -que se había comercializado libremente hasta junio- fue inferior al incremento del costo de la materia prima que contaba con un precio mínimo. Considerando valores deflactados o reales, es decir, luego de eliminar el efecto de la variación del nivel de precios de la economía, mientras el precio de la uva creció 99.45\% en 1945 respecto del año anterior, el del vino sólo lo hizo $66.42 \%$. Esto implicaba una reducción de los márgenes de ganancia importante para los bodegueros. No obstante los mayores despachos de vino, la tendencia descendente y sostenida de la diferencia entre los precios deflactados de exportación y de traslado muestra una reducción de la rentabilidad de los bodegueros exportadores, que pasó de 16.30 pesos m\$n por hectolitro en 1933 a 4.59 pesos m\$n en 1945. Mateu y Olguín, "Problema", 2008.

${ }^{86}$ Entrevista a Raúl de la Mota, realizada por Steve Stein y Ana María Mateu en junio de 2004. 
ninguna manera, eso es una locura, nos va a crear problemas de competencia." Un día fui citado a una reunión hasta que uno dijo: "[...] yo tengo la solución: nosotros estamos cometiendo un gravísimo error con la población, estamos alcoholizando a la población, estamos vendiendo vino a $13^{\circ}, 13^{\circ}$ 1/2 y eso es alcoholizar a la gente." Dijo: "yo tengo acá una revista en donde dice que los vinos de mesa que se consumen en Francia tienen $10^{\circ}$ o $10^{\circ} 1 / 2$. Si a nosotros nos permiten bajar a $12^{\circ}$, nosotros vamos a hacer crecer la producción y a abastecer el mercado.” El director de las Oficinas Químicas Nacionales, que estaba ahí, se levantó y dijo que eso era una barbaridad, que eso iba a ser un fraude escandaloso y dijeron: "Bueno, proponga otra solución." Dijo: "Bueno hagan lo que quieran. Las bodegas hicieron un aguamiento, no bajaron un grado sino que lo bajaron a tres grados."

Así fue que, en 1949 se fijaron condiciones para vinificar con menos de $12^{\circ}$, a la par que en 1951 los vinos finos y reserva suplieron el faltante de vino común en los centros de consumo. ${ }^{87}$ En Buenos Aires se vendían vinos con 8 o $9^{\circ}$ por un proceso de estiramiento tanto en los centros de consumo como en los de elaboración. El "gusto" del consumidor estaba en crisis por la escasez del producto unido a la poca exigencia del público.

Otra de las controvertidas medidas implementadas fue la expropiación de vinos comunes de Mendoza y San Juan, ${ }^{88}$ cuya puesta en práctica significó para el CVN arrasar con el derecho a la propiedad privada en la industria vitivinícola y constituyó la ratificación de la participación del Estado como órgano rector de la economía.

El profundo desacuerdo de la entidad gremial con el control de precios fue el origen del principal conflicto durante el periodo peronista. La pulseada entre el gobierno y los bodegueros fue reflejada por el diario mendocino Los Andes que llegó hasta a hablar de "asfixia industrial". Las quejas de la entidad eran justificadas en detallados análisis de costos y rentabilidad que los llevaba a sostener que se estaban lesionando los derechos de propiedad y que estaban trabajando a pérdida. Frente a esta situación, y antes de que se fijara el precio para la uva expresaba "[...] que todavía estamos a tiempo, si se obra con prudencia, y la uva se vende a un valor

${ }^{87}$ Centro Vitivinícola Nacional, Vinos, Viñas y Frutas, núm. 549, junio de 1951, p. 517.

${ }^{88}$ El gobierno peronista, con el fin de mantener los controles de precios y debido a que algunos comerciantes de vino decidían retirar sus productos del mercado por las constantes pérdidas que les ocasionaba el persistente aumento de la inflación, había dictado el Decreto núm. 5.851 del 8 de marzo de 1949 que lo autorizaba a adoptar las medidas necesarias para asegurar el "normal" abastecimiento de vinos comunes. El 7 de septiembre de 1949 dio aplicación al decreto que disponía la expropiación de los vinos comunes que hubieran en las provincias de Mendoza y San Juan cuando a juicio del Ministerio de Industria y Comercio de la Nación no se encontraran satisfechas las necesidades de la demanda. Ibid., noviembre de 1949, p. 233. Esta medida fue renovada en 1949 por el Decreto nacional núm. 30.106. En 1951 se estableció el sistema de cupos para la liberación de los vinos. Para el caso de San Juan, véase Borcosque, "Empresarios", 2008. 
que guarde relación con los precios máximos fijados para el vino, dejando un margen prudente de utilidad para todos aquellos que intervienen en su industrialización, comercialización y venta al público. De no ocurrir así, se operará un fuerte retraimiento en las actividades, con disminución del empleo de la mano de obra." ${ }^{89}$ Para sostener su postura, en agosto de 1952 calcularon que el expendedor se quedaba con 30\% del precio de venta al consumidor y señalaba además los recargos de 35 a 55\% sobre el precio final que realizaban las casas de comidas, además de $22 \%$ más por el "laudo gastronómico". ${ }^{90}$

La entidad elevó sus reclamos también en torno a los efectos negativos de la imposición nacional y provincial y por la discriminación del vino en relación con otros productos de gran consumo en el país. ${ }^{91}$ Sostuvo que el vino no recibía protección estatal, que se veía afectado por el retorno de prácticas que habían sido eliminadas con la unificación de impuestos internos y que además se encontraba altamente gravado: "En la industria del vino se comienza por la compra de uvas, con operaciones que son motivo de contrato sujeto al sellado nacional o provincial; practicada la elaboración aparecen los impuestos de inspección y análisis; solicitudes de traslado que pagan sellado; embotellado y estampillas de Impuestos Internos; patentes de locales de expendio, certificados de sanidad, libretas de control, etc.". Todo ello "incide sobre el precio de un producto que todavía no ha caído al mercado y que ya aparece sobrecargado en su costo originario por la acción del Estado que se proclama su protector" ${ }^{92}$

En julio, en carta al presidente Juan Domingo Perón, ${ }^{93}$ cautamente le reconocían los méritos de la política económica y le pedían la liberación de los controles de precios afirmando que la única solución era el incremento de la producción. En marzo de 1950, con mayor firmeza, sostenían que se atisbaba una crisis que podría tener caracteres ruinosos por la notoria falta de materia prima ya que la viña no era rentable por el costo de la tarea agrícola, el incremento del precio de la tierra, de los insumos, de los salarios, y que se estaba produciendo un reemplazo por olivares y frutales.

La revista del CVN reproducía además las cartas con reclamos enviadas a las autoridades nacionales y al mismo presidente Perón, así como también la publicación permanente de los decretos y resoluciones que afecta-

${ }^{89}$ Centro Vitivinícola Nacional, Vinos, Viñas y Frutas, año XLIII, núm. 497, febrero de 1947, p. 452.

${ }^{90} \mathrm{Ibid}$., año XLVIII, núm. 563, agosto de 1952, p. 101.

${ }^{91}$ Señalaba que en el presupuesto nacional y provincial de 1949 se habían incluido recargos y nuevos gravámenes al vino a pesar de que había sido declarado un bien de primera necesidad para la "alimentación del pueblo", como había ocurrido con la carne, el pan y el azúcar que eran industrias protegidas. Ibid., año XLIV, núm. 523, abril de 1949.

${ }^{92}$ Ibid.

${ }^{93}$ Firmada por Augusto Martínez y José Nerviani en nombre de la AVA, 3 de agosto de 1949. Ibid., año XLV, núm. 527, agosto de 1949, p. 86. 
ban al sector, para informar a sus asociados. A partir de $1953^{94}$ el clima de mayor estabilidad posibilitó también retomar otros temas, como el de la exportación de vino al extranjero. Fue en ese momento en el que la Corporación expresó su disconformidad a los ministros de Industria y Comercio y de Comercio Exterior por no haberse incluido al vino en el convenio comercial firmado con Brasil, a pesar de los pedidos de esta entidad, ${ }^{95}$ que consideraba indispensable la apertura de mercados en el exterior y el apoyo crediticio de los bancos oficiales para impulsar el almacenamiento de vinos, a plazos largos e intereses reducidos.

\section{LA REGULACIÓN DE LAS RELACIONES LABORALES: ESTATUTOS Y CONVENIOS COLECTIVOS DE TRABAJO}

En el proyecto de Estado peronista, la economía se encontraba subordinada a una lógica política que pretendía evitar la lucha de clases promoviendo la justicia social mediante la intervención estatal, tarea ya iniciada por Perón antes de su llegada al gobierno nacional. El incremento del poder adquisitivo de los salarios era entendido como condición indispensable para el desarrollo social y fue uno de los ejes de la economía justicialista para evitar el peligro de una crisis de subconsumo. Las políticas expansivas y redistributivas fueron acompañadas por los convenios laborales en las distintas industrias del país, la creación de los tribunales de trabajo y un régimen de asociaciones profesionales que sentó las bases del poder de los sindicatos. ${ }^{96}$ Sin embargo, estas políticas tuvieron su techo en 1949 cuando se clausuró la etapa ascendente de la economía argentina y se inició la carrera inflacionaria.

En el caso de los trabajadores vitivinícolas, un decreto provincial de $1943^{97}$ fijó el salario mínimo de los obreros agrícolas, y fue renovado al año siguiente. Dos años más tarde, en estrecha relación con los problemas inflacionarios, el 20 de marzo de 1945 se firmó el primer convenio colectivo de trabajo acordado entre el gobierno nacional y las principales organizaciones empresarias y gremiales, entre ellas, el CVN, la Asociación de Comerciantes de Vinos, el Sindicato Obrero de la Industria Vitivinícola y la Confederación General del Trabajo de la República Argentina. A pesar de que las principales provincias productoras eran Mendoza y San Juan, el convenio involucró solamente a los obreros de la Capital Federal y esta-

\footnotetext{
${ }^{94}$ Ibid., año XLIX, núm. 581, febrero de 1954, p. 381.

95 Ibid., año XLVIII, núm. 571, abril de 1953, p. 421.

${ }^{96}$ Para un estudio del gremialismo vitivinícola, véase Garzón, "Dispersión”, 2011.

${ }^{97}$ Mendoza, Decreto provincial núm. 767-G, julio de 1943, y 279-G, febrero de 1944.
} 
bleció salarios para los peones, obreros y personal de las bodegas y empresas fraccionadoras ${ }^{98}$ con un importante grado de detalle en relación con la tipicidad de las tareas y a la antigüedad. Además preveía el otorgamiento de viáticos para los repartidores que almorzaran fuera de su domicilio, regulaba la jornada laboral y las horas extras y establecía las condiciones de despido y el reconocimiento del Sindicato Obrero de la Industria Vitivinícola por parte de la Asociación de Comerciantes del Vino. ${ }^{99}$

Con posterioridad, el gobierno peronista impulsó la firma de numerosos acuerdos entre los gremios de trabajadores del sector y las organizaciones empresarias. Las relaciones laborales entre contratistas y patrones fueron reguladas por el Estatuto de Contratistas de Viña y de Frutales para la Provincia de Mendoza, el 30 de septiembre de 1946, que estableció los derechos y obligaciones de cada parte, reguló sus trabajos ordinarios y extraordinarios, sus condiciones de alojamiento, su derecho sobre la producción de uva, sus remuneraciones mínimas y estableció una suma fija, en función del número de hectáreas bajo su cuidado y otra variable, relacionada con el volumen de producción obtenida, y las condiciones de celebración, duración y rescisión de los contratos. ${ }^{100}$

Los primeros convenios colectivos de trabajo de la industria vitivinícola argentina tuvieron un alcance territorial parcial. Casi dos años después del convenio para los trabajadores de la Capital Federal, se firmó otro para la industria vitivinícola de Mendoza que afectó a 8000 trabajadores, con la participación de los empresarios en la comisión de estudios y que estableció los salarios y el escalafón para obreros ${ }^{101}$ y para empleados administrativos, el régimen de trabajo y los salarios para toneleros, la asignación del salario familiar, los beneficios por accidente y enfermedad y otras disposiciones generales. ${ }^{102}$ A los dos meses ${ }^{103}$ se suscribió un convenio de emergencia con la participación de la Asociación de la Industria

\footnotetext{
${ }^{98}$ Incluía choferes, conductores de chatas (tracción a sangre), repartidores, ayudantes de repartidores, obreros especializados, toneleros, mecánicos, electricistas, foguistas y destajistas.

${ }_{99}$ Centro Vitivinícola Nacional, Vinos, Viñas y Frutas, año XXXIX, núm. 476, abril de1945, pp. 352-357.

${ }^{100}$ El detalle de la disposición puede ejemplificarse con lo establecido para los trabajos extraordinarios. Ibid., 1947, pp. 386-390. Antes de la Ley provincial núm. 1.578 de 1946, se dictó el Decreto 496-G de 1945 que constituyó el primer cuerpo legal, aunque incompleto, de los contratistas en tanto trabajadores. Anales de Legislación Argentina, Repertorio, 1945, t. 5, pp. 987-989.

${ }^{101}$ Obreros comunes, conductores de carros, degolladores de champagne, tapadores, engrapadores, cámaras frigoríficas, foguistas, calafateadores, apretadores, cuidadores de máquina frigorífica, obreros con oficio.

${ }^{102}$ El convenio colectivo fue firmado el 15 de enero de 1947 pero regiría a partir del 1 de octubre de 1946, por el término de un año. Centro Vitivinícola Nacional, Vinos, Viñas y Frutas, 1947, pp. 431-433.

${ }^{103}$ El 22 de enero de 1947 se produjo un paro de diez días por parte del personal administrativo y obrero de las bodegas a pesar de la vigencia de los convenios de trabajo. Los Andes, 1 de febrero de 1947.
} 
Vitivinícola Argentina, que estableció aumentos para los obreros de todo el país, con excepción de Mendoza y Tucumán, pero que expresaba la intención de suscribir en un futuro un convenio general que incluyera a toda la industria. ${ }^{104}$ Hacia finales de 1947, los industriales habían firmado dos nuevos convenios, ${ }^{105}$ que generalmente siguieron el ritmo de la carrera inflacionaria y que tuvieron el mismo espíritu de los firmados para el resto de las industrias del país.

Adicionalmente, a fines de 1948 la Comisión Nacional de Trabajo Rural modificó las remuneraciones de los contratistas de viñas y de frutales y aumentó la remuneración fija y variable del contratista de viña, estableciendo diferencias de acuerdo con factores como las variedades de viñas, la existencia de viñas nuevas, frutales intercalados, mugrones, rodrigones, herramientas y animales de su propiedad. ${ }^{106}$ En marzo de 1949, el ministro de Trabajo y Previsión dictó una resolución por la cual consideraba justo el petitorio de la Federación de Obreros y Empleados Vitivinícolas y Afines, modificatorio del convenio en vigencia para esa actividad. En la parte dispositiva se establecieron categorías para las distintas actividades de la industria, fijándose las asignaciones de acuerdo con las especialidades, la antigüedad, y el régimen de labor; el pago de viáticos y los sueldos y condiciones de trabajo para el personal empleado de acuerdo con su especialización y antigüedad y para el trabajo a destajo. Por último, la resolución estableció el salario familiar y fijó la suma que debía abonar el empleador por el nacimiento de cada hijo de empleado u obrero varón y la retribución por cada hijo menor de 16 años. En 1950 se firmó otro convenio colectivo que benefició a todos los trabajadores de la industria vitivinícola del país, con base en un estudio realizado entre el sector obrero y el patronal. ${ }^{107}$

La intención del gobierno con estas medidas fue mantener el poder adquisitivo de la clase trabajadora, cuya tasa de sindicalización había aumentado y por lo tanto también su poder de presión. En este sentido, es demostrativo el decreto del poder ejecutivo nacional de 1948 que estableció que el aumento de las retribuciones al personal debía ser absorbido por la empresa y no trasladado a los precios. ${ }^{108}$

¿Cuál fue la postura del CVN, transformado en la Asociación Vitivinícola Argentina, frente al aumento de los salarios? En primer lugar, de-

${ }^{104}$ El convenio colectivo fue firmado el 12 de marzo pero regiría a partir del 1 de febrero de ese año. Centro Vitivinícola Nacional, Vinos, Viñas y Frutas, 1947, pp. 551-552.

${ }^{105}$ En el mes de septiembre la asamblea de la Asociación Vitivinícola Argentina había aprobado un nuevo convenio de aumento de jornales y sueldos a los obreros de ambos sexos, obreros jornalizados y empleados administrativos, y el 9 de octubre puso en vigencia otro. Ibid., 1947, p. 165.

${ }^{106}$ Ibid., año XLII, núm. 520, enero de 1949, pp. 314-316.

${ }^{107}$ Ibid., año XLV, núm. 534, marzo de 1950.

${ }^{108}$ Hace referencia al Decreto nacional núm. 15.717 en Argentina. Anales de Legislación Argentina, Repertorio, núm. 514, julio de 1948. 
bemos remarcar que la entidad empresarial participó de la firma de los convenios colectivos, a la par que expresaba sus quejas y reclamaba por el equilibrio entre capital y trabajo. Así, en 1947 sostuvo que la industria por sí misma había mejorado los salarios antes de que los trabajadores lo reclamaran y advirtió sobre "la intromisión de factores que no son normales en la vida de la industria vitivinícola y van precisamente contra las conquistas de orden social que se desean afianzar". ${ }^{109}$ Para la misma época, también expresó en relación con las huelgas: "pedir por pedir traduce siempre una conducta carente de lógica, que rebaja la jerarquía del que lo solicita y lo lleva a exhibir una condición mendicante", lamentándose de que el gobierno nacional brindaba su ayuda para que otras actividades pudieran aumentar los sueldos, mientras que la vitivinicultura debía soportar sola las mayores cargas. ${ }^{110}$

En 1949, en una presentación ante el Consejo Económico Nacional, criticó que en un gobierno que hablara de justicia social, la mayor carga inflacionaria la debieran soportar los empresarios: "Frente a las continuadas y crecientes mejoras obreras, la situación patronal es de irritante injusticia, máxime en una época que ha dado en llamarse de igualdad." 111

Ya en la década de 1950 la entidad expresó al ministro de Industria y Comercio y al presidente del Consejo Nacional Económico su "buena voluntad" al acceder al pedido de los empleados de aumentos de salarios, pero también reclamó al gobierno por una elevación de los precios máximos a fin de poder cumplir con la medida. ${ }^{12}$ En esos días, para la Fiesta de la Vendimia, el ministro de Industria y Comercio, José Constantino Barros ${ }^{113}$ ratificó el rumbo de la política justicialista afirmando que "el obrero mal remunerado es un vencido para sí y su familia". Sostuvo que en la política argentina, cristiana y democrática había correspondido a Mendoza la más alta participación,

pero hubiese sido insuficiente la exuberancia del predio mendocino y el sacrificio de sus hijos [...] si el gobierno del general Perón no hubiese asegurado a todos los trabajadores del país remuneraciones que les permitieran con holgura la satisfacción de sus necesidades, que tantas veces les fueran negadas [...] De esta concepción fecunda, lógica y armoniosa que inspira la política retributiva y distributiva del peronismo tienen que surgir las palancas de nuestra liberación, para que se cumplan inexorablemente los preceptos de la Constitución justicialista, [...]

\footnotetext{
${ }^{109}$ Centro Vitivinícola Nacional, Vinos, Viñas y Frutas, 1947, p. 595.

${ }^{110}$ Ibid., 1947, pp. 328 y 329.

111 Ibid., 1949, pp. 513-514.

112 Ibid., 1950.

${ }^{113}$ Diario Los Andes, 27 de marzo de 1950.
} 
haciendo de la sociedad argentina además de una "nueva y gloriosa nación”, también una "nación libre, justa y soberana".

Para 1952 la situación había cambiado, y en febrero se congelaron los precios de los artículos de primera necesidad y se fijaron acuerdos por dos años sobre salarios. Evidenciando una preocupación por la calidad, en febrero de $1953^{114}$ la Dirección de Vinos remarcó que el Segundo Plan Quinquenal apuntaba a la obtención de caldos de alta calidad en volumen suficiente para el mercado interno y a precios accesibles a la masa consumidora del país y que, por lo tanto, se hacía necesario proseguir "la ejecución de la firme política del gobierno de la nación de afianzar la industria dotándola de un régimen que jerarquizará la calidad de sus productos, defender los legítimos intereses de la masas consumidora [...] y permitir a nuestros productos competir con ventaja en los mercados del exterior".

$\mathrm{Al}$ año siguiente, al celebrarse el día del Obrero Vitivinícola ${ }^{115}$ Perón elogió por radio a los trabajadores de la industria y resaltó sus consultorios médicos, sus proveedurías, las viviendas para sus afiliados y los beneficios sociales que ya estaban vigentes, expresando con dureza que ante esos intereses políticos, algunos, se dedicaban exclusivamente a promover un clima de subversión entre los afiliados. Al final del ciclo peronista, en 1955, se insistió en la colaboración entre empresarios y trabajadores, respaldándose en que la productividad era una forma de justicia social reconocida por la Organización Internacional del Trabajo (OIT) y que permitía mayores salarios, reducción de horas de trabajo, y precios más bajos en algunos productos.

Terminados los problemas de abastecimiento, en $1954^{116}$ el gobierno consideró que era necesario superar la etapa en que la intervención del Estado debió hacerse más rigurosa para asegurar una distribución justa de los bienes. Correspondía ahora devolver a la industria la libre comercialización de sus productos y, por ello, se dejaba sin efecto a partir del 1de octubre el régimen de cuotas para el expendio de vino común. ¿Había llegado el momento de mirar al exterior, lejos del consumo doméstico?

\section{CONCLUSIONES}

El CVN exhibió durante la década de 1930 una complacencia, a veces disimulada y otras desembozada, con las medidas regulatorias referidas al

${ }^{114}$ Centro Vitivinícola Nacional, Vinos, Viñas y Frutas, año XLVIII, núm. 570, marzo de 1953, p. 409. Resolución núm. 166 que hace referencia a la clasificación de vinos.

${ }^{115}$ Diario Los Andes, 2 de febrero de 1954. Véase Garzón, "Dispersión”, 2011.

${ }^{116}$ Centro Vitivinícola Nacional, Vinos, Viñas y Frutas, año L, núm. 588, 21 de septiembre de 1954, p. 259. Resolución núm. 103. 
control de la oferta, aunque se opuso a la Sociedad Vitivinícola planeada por Bunge, tal vez porque aún no veía en peligro inminente la rentabilidad del negocio y porque temía que una sociedad anónima reguladora les creara una competencia gremial. Dejó pasar sin pena ni gloria a la Comisión Autónoma de Defensa Vitivinícola pero apoyó a la Junta Reguladora, aunque las medidas diseñadas por las tres entidades eran similares y no apuntaban a un cambio en el modelo ni a una redistribución de las ganancias.

¿Fue necesario un mayor temor de que "la miseria de la abundancia" se llevara con ella a las grandes bodegas y a los bancos, que se habían convertido en actores importantes de la industria? ¿ Tuvo mayor consenso una regulación impuesta por una ley nacional y por un gobierno conservador, afín a los intereses políticos del CVN? ¿Es por ello que no percibieron en estas medidas un avance contra las libertades individuales y la libertad de mercado?

Todas las regulaciones de esos años estuvieron estrechamente vinculadas a la expansión excesiva de la oferta de vinos y a la depresión de la demanda en relación con la capacidad adquisitiva de los salarios. Los controles aplicados fueron fruto de una "desesperación colectiva" 117 y dejaron para más adelante los consejos de los "expertos" sobre la oportunidad de incorporar mejoras en el proceso productivo, controlar la calidad de los caldos, promover el consumo de vinos y fomentar el cooperativismo para un desarrollo más armónico. Los instrumentos más utilizados fueron los que permitieron reducir rápidamente la oferta de vinos a través de la compra de elevadas proporciones de uva y enormes volúmenes de vinos y de la extirpación de viñedos, afectando el futuro de la industria.

Sin embargo, las medidas sólo fueron exitosas en un plazo que no superó los tres años, ${ }^{118}$ retroalimentaron la dinámica de la organización industrial que había estado presente desde fines del siglo XIX y no contrarrestaron el poder de mercado de los grandes bodegueros y de los intermediarios comerciales y la debilidad de los viñateros. Los costos de las fallas de la regulación -tanto estatal como privada- fueron superiores a los costos de las fallas del mercado y no evitaron la "captura" del regulador por parte de las grandes empresas. Después de la década de 1930, la industria perdió posicionamiento en el ámbito nacional, sus existencias aumentaron dramáticamente, la capacidad de vasija ociosa se incrementó y los avances en la integración de los viñateros con el eslabón de elaboración no fueron significativos. Así, de 1913 a 1942, Mendoza pasó a elaborar de 80 a 71\% del vino del país, las existencias de vinos aumentaron de 47 a 95\% -debido en parte a que la adulteración continuaba incrementando la producción-,

${ }^{117}$ Diario Los Andes, 30 de abril de 1945.

${ }^{118}$ Olguín, "Estado", 2012. 
la capacidad de vasija vinaria utilizada se redujo de 55 a $38 \%$ y la uva vinificada comprada descendió de 62 a 44 por ciento. ${ }^{119}$

La explicación para la tolerancia y el apoyo ante medidas que sólo actuaron en la coyuntura, tiene sus raíces en un contexto sectorial difícil, en donde el futuro del modelo estaba en riesgo. La sobreproducción y la baja calidad, los bajos precios, la caída del consumo por la recesión económica, el endeudamiento bancario, implicaban que sólo si se reducía el tamaño de la industria (extirpando, reconvirtiendo, eliminando y hasta tirando vino por las acequias), algunas empresas, las más importantes, podrían sobrevivir. Es por ello, que a nuestro juicio, la actitud del CVN ante la Junta Reguladora Nacional se relaciona con que era la única posibilidad que les quedaba para mantener buenos precios y un modelo que les había prodigado importantes excedentes, ya que las pérdidas las asumían los eslabones más débiles, sobre todo los viñateros sin bodega y los trabajadores, a través de la disminución del precio de la uva y de los jornales.

Una situación distinta fue la que se produjo con la llegada del peronismo, que representó un cambio fundamental en la vida del país en sus aspectos políticos, económicos y sociales. ¿Se podría trasladar este juicio hacia la vitivinicultura? ¿Los años peronistas representaron un cambio fundamental en la dinámica de la agroindustria? Aunque no podemos hablar de una política industrial al estilo de la propuesta por la Junta Reguladora, es indudable que las regulaciones afectaron la oferta y la demanda y provocaron una redistribución de excedentes. En los industriales, el optimismo inicial se perdió y los precios máximos al vino, ya con antecedentes para otros productos, y los aumentos de salarios convencieron a los bodegueros de que trabajaban a pérdida y les hicieron recordar aquellas bondades del mercado que en la década de 1930 habían olvidado.

En 1949, en una presentación ante el Consejo Económico Nacional para defender la solución integral a los problemas de la industria mediante la libertad de comercio, ${ }^{120}$ el CVN llegó a decir que hasta la inflación era una consecuencia de la regulación y criticó que en un gobierno que hablara de justicia social, la mayor carga inflacionaria la debieran soportar los empresarios: "Frente a las continuadas y crecientes mejoras obreras, la situación patronal es de irritante injusticia, máxime en una época que ha dado en llamarse de igualdad." 121

Cansados de que sus voces no se oyeran, en 1954 expresaron con dureza: "No tiene nada de alentador el panorama que presenta la industria. Por un lado trabas creadas con espíritu que no condice con el que anima

\footnotetext{
119 Ibid.

${ }^{120}$ Diario Los Andes, mayo de 1949, pp. 473-474.

${ }^{121}$ Ibid., junio de 1949, pp. 513-514.
} 
las manifestaciones del presidente Perón, en el sentido de apoyar al mejor desarrollo vitivinícola." La liberalización del comercio era, a juicio de la entidad, un derecho constitucional ${ }^{122}$ y la AVA se enorgullecía de ser el primer organismo gremial en haber puesto reparos al avance del gobierno sobre los derechos individuales en innumerables presentaciones, reglamentos y normas que condicionaban el ordenamiento $y$, al mismo tiempo, se preguntaba, des que no importa para el país la crisis vitivinícola ni tampoco destruir el espíritu de lucha de quienes con sus esfuerzos dieron prestigio? ${ }^{123}$ ¿Por qué la entidad exhibió una postura tan dura ante los controles de precios y de salarios del gobierno peronista, al que calificaba como segunda tiranía? Los precios máximos para el vino, el aumento de salarios y la reglamentación de las relaciones laborales impactaron negativamente sobre sus costos internos en medio de un consumo creciente que no alcanzaba a ser satisfecho y al cual siempre habían aspirado. Los controles opacaron la consideración de otras medidas, como el crédito, que podrían haber sido aprovechadas como ocurrió con otras industrias. ${ }^{124}$ Junto a las medidas económicas, el antiperonismo se había colado en las filas de la entidad con mayor "abolengo", seguramente influenciada o atemorizada por los graves conflictos con la Unión Industrial, intervenida en 1946.

El clima de fervor político contribuyó a exacerbar los ánimos y a politizar los reclamos. La visita de Perón y Evita en la vendimia de 1947 ocupó las páginas de la prensa y los actos públicos mostraron la adhesión de los trabajadores a la economía justicialista. iMendoza era peronista! En 1949, cuando el presidente volvió a venir a Mendoza para inaugurar el Congreso de Filosofía, la prensa convocó a los industriales vitivinícolas a través de un aviso destacado:

El Centro de Bodegueros de Mendoza, la Sociedad de Bodegueros Trasladistas, Centro de Bodegueros del Este y Centro de Viñateros Zona Norte, cumplen en dirigirse a sus asociados y a todos los productores e industriales vitivinícolas de la Provincia, para invitarlos a colaborar con las autoridades departamentales, poniendo a disposición de las mismas sus automotores para efectuar el transporte de los concurrentes a la concentración pública que se realizará el próximo sábado en la Plaza Independencia a las $18 \mathrm{hrs}$ en homenaje del excelentísimo señor presidente de la nación y autoridades nacionales. ${ }^{125}$

\footnotetext{
${ }^{122}$ Ibid., junio de 1944, p. 425.

${ }^{123}$ Ibid., febrero de 1954 , p. 381.

${ }^{124}$ Girbal-Blacha, Estado, 2002.

${ }^{125}$ Ibid., 8 de abril de 1949.
} 
Evidentemente la racionalidad empresaria permitía estas posturas oscilantes y pragmáticas y la defensa a la libertad de mercado no tenía mucho que ver con la demostración de cortesía al presidente Perón y a su esposa. ¿Tendría esta colaboración en medio de tantos reclamos algo que ver con el postulado peronista "Para que cada argentino sepa lo que debe hacer...?" 126

Sin embargo, el CVN siguió en su defensa de la libertad de comercio y en el ideario de Mayo. La mejor muestra de ello fue que luego de la "reparación moral" de la revolución libertadora, crearon, subsidiado por la AVA, el Centro de Estudios sobre la Libertad, cuyos objetivos fueron el estudio y la difusión de la filosofía de la libertad, así como también el esclarecimiento de la opinión en materia económica. ${ }^{127}$

\section{FUENTES CONSULTADAS}

Siglas

AVA Asociación Vitivinícola Argentina.

COVIAR Corporación Vitivinícola Argentina.

CVN Centro Vitivinícola Nacional.

SOEVA Sindicato de Obreros y Empleados Vitivinícolas y Afines.

OIT Organización Internacional del Trabajo.

\section{Hemerografía}

Los Andes, Mendoza, Argentina.

\section{Revistas y boletines}

Álbum del Centro Vitivinícola Nacional, La Vitivinicultura Argentina en 1910, Mendoza, Argentina.

Anales de Legislación Argentina, Repertorio, años 1930-1955, Argentina.

Boletín de la Sociedad de Defensa Vinícola Nacional, Argentina, 1904.

Boletín Centro Vitivinícola Nacional, Argentina, 1908.

Centro Vitivinícola Nacional, Revista Agrícola, Industrial y Comercial, 1917.

${ }^{126}$ Ibid., 19 de febrero de 1952.

${ }^{127}$ Centro Vitivinícola Nacional, Vinos, Viñas y Frutas, diciembre de 1960, p. 247. A principios del siglo XXI se fusionaría con el Centro de Bodegueros de Mendoza para formar Bodegas de Argentina (2001). 
Centro Vitivinícola Nacional, Revista Agrícola, Industrial y Comercial, 1920.

Centro Vitivinícola Nacional, Revista Mensual Ilustrada, 1926.

Centro Vitivinícola Nacional, Agrícola, Revista Mensual Ilustrada de Agricultura, Comercio e Industria, 1929-1935.

Centro Vitivinícola Nacional, Vinos, Viñas y Frutas, Revista Ilustrada de Enseñanza, Información y Propaganda Agrícola, julio de 1940.

Centro Vitivinícola Nacional, Vinos, Viñas y Frutas, Revista Mensual Ilustrada, 1945-1954.

Centro Vitivinícola Nacional, Vinos, Viñas y Frutas, 1960.

Diario de sesiones, Cámara de Diputados, 1934, Argentina.

\section{Bibliografía}

ACUÑA, CARlos H., “¿Racionalidad política versus racionalidad económica? Notas sobre el modelo neoclásico de acción colectiva y su relación con la teoría y método del análisis político", Revista Argentina de Ciencia Política, Universidad de Buenos Aires, núm. 1, noviembre de 1997, pp. 31-55.

y LAURA GOLBERT, "Empresarios y política, 2a. parte, Los empresarios y sus organizaciones ¿̇qué pasó con el Plan Austral?”, Boletín Informativo Techint, Organización Techint, núm. 263, mayo-agosto de 1990, Buenos Aires, pp. 33-52.

Anuario. Síntesis Estadística y Geográfico-Económica, Mendoza, Ministerio de Economía, Instituto de Investigaciones Económicas y Tecnológicas, años 1952, 1955 y 1956

Arata, Pedro N., "Investigación vitivinícola", Informes presentados al ministro de Agricultura por la Comisión Nacional compuesta por el Dr. Pedro N. Arata (presidente), Ulises Isola (secretario), Luciano Garola, José Lavenir y Domingo Simois (vocales), en Anales del Ministerio de Agricultura, núm. 1, t. I., sección Comercio, Industrias y Economía, Argentina, Buenos Aires, Ministerio de Agricultura, 1903.

AzPiazu, Daniel y EdUardo Basualdo, "El complejo vitivinícola en los noventa: potencialidades y restricciones" en el marco del proyecto entre el gobierno de Holanda y la Comisión Económica para América Latina y el Caribe (HOL/97/ S93) Pequeñas y Medianas Empresas Industriales en América Latina y el Caribe y Competitividad Internacional, Santiago, CEPAL, marzo de 2001.

, Estudios sectoriales. Componente: industria vitivinícola, Buenos Aires, Comisión Económica para América Latina y el Caribe, marzo de 2003 (Documento de trabajo, Estudio 1.EG.33.6).

BALÁn, JoRge y NANCY LóPez, "Burguesías y gobiernos provinciales en la Argentina. La política impositiva de Tucumán y Mendoza entre 1873 y 1914”, Desarrollo Económico. Revista de Ciencias Sociales, Instituto de Desarrollo Económico y Social, vol. 17, núm. 67, 1977, Buenos Aires, pp. 391-435.

Barrio, PAtricia E., "Hacia la consolidación del Mercado Nacional de Vinos. Modernización y desarrollo del sector vitivinícola de Mendoza (Argentina), 1900-1914”, 
Espacios Historia, Universidad Nacional de la Patagonia Austral, núm. 26, 2003, Río Gallegos, pp. 33-60.

, "Crisis económica y estrategias empresariales. Bodegueros mendocinos a principios del siglo Xx", Cuadernos de Historia. Serie Economía y Sociedad, Universidad de Córdoba, núm. 7, 2005, Córdoba, pp. 31-69.

, "Una crisis de la vitivinicultura mendocina a principios del siglo XX (1900-1903)" en Ana María Mateu y Steve Stein, El vino y sus revoluciones. Una antología histórica sobre el desarrollo de la industria vitivinícola argentina, Mendoza, Universidad Nacional de Cuyo, 2008.

, Hacer vino. Empresarios vitivinícolas y Estado en Mendoza (1900-1912), Rosario, Prohistoria, 2010.

BELTRÁn, GASTÓn, "La acción empresarial en el contexto de las reformas estructurales de las décadas de los ochenta y noventa en Argentina", tesis de doctorado en Ciencias Sociales, Argentina, Universidad de Buenos Aires, 2007.

Belini, Claudio, "Estado y política industrial durante el primer peronismo" en PATRIcia Berrotarán, Aníbal Jáuregui y Marcelo Rougier, Sueños de bienestar en la nueva Argentina. Las políticas públicas durante el peronismo, 1944-1955, Buenos Aires, Imago Mundi, 2004.

, La industria peronista, Buenos Aires, EDHASA, 2009.

Borcosque, LÍA AleJANDRA, "Los empresarios del vino y la vitivinicultura sanjuanina: el Centro de Bodegueros y Exportadores de San Juan” en JAVIER BALSA, Graciela Mateo y María Silvia Ospital (coords.), Pasado y presente en el agro argentino, Buenos Aires, Lumiere, 2008.

BRAGONI, BEATRIZ, "Redes, inmigración y movilidad social en Mendoza: racionalidad empresaria y modos de relación política de una parentela de origen finisecular, 1880-1930", Estudios Migratorios Latinoamericanos, Centro de Estudios Migratorios Latinoamericanos, núm. 24, agosto de 1993, Buenos Aires, pp. 171-203.

“'Meritorios españoles, ejemplares nobles'. Inmigración, redes y mercado: notas sobre la formación de emporios vitivinícolas en Mendoza, 1860-1940" en Alejandro Fernández y José Moya (eds.), La inmigración española en la Argentina, Buenos Aires, Biblos, 1999.

"El estímulo del mercado en la transformación empresaria. Consideraciones a raíz del negocio vitivinícola en Mendoza, 1880-1940” en FERNANDO Jumar (ed.), Empresarios y empresas rurales siglos XIX y XX, Buenos Aires, Universidad Argentina de la Empresa, 2002.

"Familia, negocios y empresas en la literatura histórica referida al caso argentino. Balance de un recorrido" en JORGE GELMAN (coord.), La historia económica Argentina en la encrucijada. Balances y perspectivas, Buenos Aires, Prometeo/ Asociación Argentina de Historia Económica, 2006.

, Ana María Mateu, Patricia Olguín y Virginia Mellado, "Siguiendo los pasos de la crisis: origen y conformación de las entidades empresarias vitivi- 
nícolas", XXI Jornadas de Historia Económica, Buenos Aires, Asociación Argentina de Historia Económica/Universidad Nacional de Tres de Febrero, 2008, [CD].

"Asociacionismo empresario en el siglo Xx: origen y formación de las entidades vitivinícolas argentinas" en ANA MARÍA MATEU (comp.), Vinos y competitividad agroindustrial. Un largo camino, Mendoza, Inca, 2011.

Bunel, Jean, Marie-France Prévôt Schapira y Susana Peñalva, "Los empresarios frente a las nuevas políticas económicas. El caso de la provincia de Mendoza (Argentina)", Revista Mexicana de Sociología, Universidad Nacional Autónoma de México, vol. 57, núm. 74, Reforma económica y empresariado en América Latina, octubre-diciembre de 1995, México, pp. 227-240.

Cerdá, JuAn Manuel, "El trabajo agrícola en dos épocas diferentes de modernización. La vitivinicultura mendocina entre 1900-2000” en JAVIER BALSA, GRACIELA Mateo y María Silvia Ospital, Pasado y presente en el agro argentino, Buenos Aires, Lumiere, 2001.

"Mercado de trabajo y condiciones de vida en Mendoza a comienzos del siglo XX", Revista Mundo Agrario. Revista de Estudios Rurales, Universidad Nacional de La Plata, vol. 6, núm. 12, primer semestre de 2008.

CORIA, Luis A. y Lidia ForTín DE IÑOnES, "El boom vitivinícola mendocino (1883-1912) y la acción del Estado", Jornadas de Ciencias Económicas, Mendoza, Universidad Nacional de Cuyo, 1994.

Cortés Conde, Roberto, La economía política de la Argentina en el siglo xx, Buenos Aires, EDHASA, 2007.

Dossi, MARINA, "La acción colectiva de los grandes grupos económicos. Un análisis de las estrategias y comportamiento de las corrientes internas de la Unión Industrial Argentina en el periodo 1989-2002", tesis de maestría en Sociología Económica, Argentina, Universidad Nacional de General San Martín, 2007.

Fernández, Alejandro, "Los importadores españoles, el comercio de vinos y las transformaciones en el mercado entre 1880 y 1930" en ANA MARÍA MATEU y STEVe Stein, El vino y sus revoluciones. Una antología histórica sobre el desarrollo de la industria vitivinícola argentina, Mendoza, Universidad Nacional de Cuyo, 2008.

Ferrer, Aldo, La economía argentina, Buenos Aires, Fondo de Cultura Económica, 2008.

Ferro, Verónica P., Los efectos económicos de la crisis mundial de 1929 en la provincia de Mendoza, Buenos Aires, Dunken, 2008.

Fleming, William J., "The Cultural Determinants of Entrepreneurship and Economic Development: A Case Study of Mendoza Province, Argentina, 1861-1914”, Journal of Economic History, The Economic History Association, vol. 39, núm. 1, marzo de 1979, pp. 211-224.

Gajst, NATAlia, "La escuela francesa de la regulación: una revisión crítica", Revista Científica Visión de Futuro, Universidad Nacional de Misiones, año 7, núm. 1, vol. 13, Argentina, enero-junio de 2010, en 〈http://revistacientifica.fce.unam.edu.ar/ index.php>. 
Galanti, Arminio N., La industria vitivinícola argentina, Buenos Aires, Talleres S. Oswald y Cía., 1900a. Mendoza, 1900b, t. I.

Garzón Rogé, Mariana, "La experiencia formativa del Partido Peronista en Mendoza, 1946-1949" en OSCAR AELO (comp.), Las configuraciones provinciales del peronismo: actores y prácticas políticas 1945-1955, La Plata, Instituto Cultural de la Provincia de Buenos Aires, 2010.

"Dispersión, lealtad, pragmatismo; itinerario de la experiencia sindical de las entidades vitivinícolas argentinas" en ANA MARÍA MATEU (comp.), Vinos y competitividad agroindustrial. Un largo camino, Mendoza, Inca, 2011.

Gelman, JoRge (coord.), La historia económica argentina en la encrucijada, Buenos Aires, Prometeo/Asociación Argentina de Historia Económica, 2006.

Gerchunoff, Pablo y Damián Antúnez, "De la bonanza peronista a la crisis de desarrollo" en JuAn CARlos TORRE (comp.), Los años peronistas (1943-1955), Buenos Aires, Sudamericana, 2002, t. VIII.

Gerchunoff, Pablo y Lucas Llach, El ciclo de la ilusión y el desencanto. Un siglo de políticas económicas argentinas, Buenos Aires, Ariel, 2003.

Girbal-Blacha, Noemí, "Ajustes de una economía regional. Inserción de la vitivinicultura cuyana en la Argentina agroexportadora, 1885-1914", Investigaciones y Ensayos, Academia Nacional de la Historia, núm. 35, 1987. (coord.), El Estado neoconservador, el intervencionismo económico y la sociedad de los años 30, Buenos Aires, Universidad Nacional de Quilmes, 2001. (coord.), Estado, sociedad y economía en la Argentina (1930-1997), Buenos Aires, Universidad Nacional de Quilmes, 2002.

, Mitos, paradojas y realidad en la Argentina peronista. 1946-1955, Bernal, Universidad Nacional de Quilmes, 2004.

Granovetter, Mark, "Economic Action and Social Structure. The Problem of Embeddedness", American Journal of Sociology, University of Chicago, vol. 91, núm. 3, noviembre de 1985, pp. 481-510.

Heredia, Mariana, "Reformas estructurales y renovación de las elites económicas en Argentina: estudio de los portavoces de la tierra y del capital”, Revista Mexicana de Sociología, Universidad Nacional Autónoma de México, año 65, núm. 1, eneromarzo de 2003, México, pp. 77-115.

ITZCOVITZ, VictoRIA, "Las organizaciones empresarias frente al gobierno constitucional: la Cámara Argentina del Comercio y la Asociación de Bancos Argentinos” en José Nun y Juan Carlos Portantiero, Ensayos sobre la transición democrática en la Argentina, Buenos Aires, Puntosur, 1987.

Junta Reguladora de Vinos, Memoria, Buenos Aires, Argentina, Ediciones Peuser, 1935 y 1942 .

Recopilación de leyes, decretos y disposiciones sobre la industria vitivinícola, Argentina, Ministerio de Agricultura de la Nación, 1941. 
LATTUADA, MARIO, Acción colectiva y corporaciones agrarias en la Argentina. Transformaciones institucionales a fines del siglo XX, Buenos Aires, Universidad Nacional de Quilmes, 2006.

LiSSin, LAUTARO, "Acción colectiva empresaria. ¿Homogeneidad dada o construida? Un análisis a la luz del estudio de las corporaciones empresarias en la crisis del 2001", Documentos de Investigación Social, Universidad Nacional de San Martín, núm. 3, 2008, Buenos Aires.

Lucchini, María Cristina, Teodoro Blanco y Ángel Cerrá, "El pensamiento industrialista argentino en el periodo de entreguerras. El estudio de un caso: la influencia de List en Bunge", Estudios Interdisciplinarios de América Latina y el Caribe, Universidad de Tel Aviv, vol. 11, núm. 2, julio-diciembre de 2000.

MarianetTi, Benito, El racimo y su aventura. La cuestión vitivinícola, Buenos Aires, Platina, 1965.

Mateu, Ana MaríA, "Bancos, créditos y desarrollo vitivinícola", Cuadernos de Historia Regional, Universidad Nacional de Luján, Argentina, núm. 17, 1994.

"Los Arizu y su exitosa tarea de hacer la América", Actas de las Segundas Jornadas de Historia Económica, Montevideo, julio de 1999, [CD].

"Aproximación a la empresa Arizu: algunas estrategias de la conformación e incremento del patrimonio societario y familiar 1884-1920", Revista Quinto Sol, Universidad Nacional de La Pampa, año 6, núm. 6, 2002.

"Estado y vitivinicultura. Las políticas públicas de la transición. Mendoza. 1870-1890”, Travesía, Revista de Historia Económica y Social, Universidad Nacional de Tucumán, Daniel Campi y Marta Bonaudo (comps.), núms. 3-4, 2003, Tucumán, pp. 177-207.

"La vitivinicultura mendocina en 1930: entre la miseria de la abundancia y los inicios frustrados de la reconversión productiva", Actas de LASA 2006, XXVI International Congress, Puerto Rico, 2006, [CD].

"El modelo centenario de la vitivinicultura mendocina. Génesis, desarrollo y crisis (1870-1980)" en Marcelo Delfini y Daniela Dubbini, Innovación y empleo en tramas productivas de Argentina, 1a. parte, Buenos Aires, Prometeo, 2007.

"Los caminos de construcción del cooperativismo vitivinícola en Mendoza. Argentina (1900-1920)", Documento de Trabajo, núm. 176, Buenos Aires, Universidad de Belgrano, 2007, en <http://www.ub.edu.ar/investigaciones/dt_nue vos/176_mateu.pdf $>$.

"Los vinos de Arizu: el encuentro entre la oferta y la demanda", XXI Jornadas de Historia Económica, Buenos Aires, Asociación Argentina de Historia Económica/Universidad Nacional de Tres de Febrero, 2008, [CD].

"Estudio y análisis de la modalidad empresarial vitivinícola de los Arizu en Mendoza", tesis doctoral, Universidad Nacional de Cuyo, Mendoza, Argentina, 2009.

(comp.), Vinos y competitividad agroindustrial. Un largo camino, Mendoza, Inca, 2011. 
y PAmela NATAli, "Reconversión productiva y corporaciones. El caso de la vitivinicultura mendocina (1980-2004)", Terceras Jornadas de Historia de la Industria y los Servicios, Buenos Aires, 2011, [CD].

"Políticas públicas, corporaciones y reconversión vitivinícola: ¿̇encuentro o desencuentro?”, Actas del Primer Congreso Chileno de Historia Económica, Chile, Universidad Andrés Bello, 2011, [CD].

Mateu, Ana María y Patricia Olguín, "El problema no es intervenir sino cómo. Las posturas de la AVA frente al gobierno peronista”, XX Jornadas de Historia Económica, Mar del Plata, Universidad Nacional de Mar del Plata, 2008.

Mateu, Ana María y Steve Stein, "Diálogos entre sordos. Los pragmáticos y los técnicos en la época inicial de la industria vitivinícola argentina", Revista de Historia Agraria. Revista de Agricultura e Historia Rural, Universidad de Murcia/Universidad Autónoma de Madrid, núm. 39, agosto, 2006, España, pp. 267-292.

McDermott, Gerald, The Politics of Institutional Renovation and Competitive Upgrading: Lessons from the Transformation of the Argentina Wine Industry, Pensilvania, University of Pennsylvania, 2005.

Mellado, Virginia, "Empresariado y vitivinicultura: trayectoria y caída del grupo Greco” en Ana Mateu y Steve Stein (comps.), El vino y sus revoluciones. Una antología histórica sobre el desarrollo de la industria vitivinícola argentina, Mendoza, Universidad Nacional de Cuyo, 2008.

Neiman, Guillermo, Adriana Bocco y Clara Martín, "Tradicional y moderno. Una aproximación a los cambios cuantitativos y cualitativos de la demanda de mano de obra en el cultivo de vid" en Guillermo Neiman (comp.), Trabajo de campo. Producción, tecnología y empleo en el medio rural, Buenos Aires, Ciccus, 2001.

North, Douglas, Institutions, Institutional Change and Economic Perfomance, Cambridge, Cambridge University Press, 1990.

Nun, José y Mario LATTUADA, El gobierno de Alfonsín y las corporaciones agrarias, Buenos Aires, Manantial, 1991.

Olguín, PATRICIA, "Políticas públicas y empresas vitivinícolas: la privatización de Giol y la conformación de Fecovita. Primera parte: la creación de la Bodega Estatal”, Actas IV Jornadas Interdisciplinarias Estudios Agrarios y Agroindustriales, Buenos Aires, Universidad de Buenos Aires, noviembre de 2005, [CD].

"La intervención estatal en los mercados vitivinícolas. La función de regulación de las Bodegas y Viñedos Giol. Mendoza, Argentina (1954-1974)", Territorios del Vino, Universidad de la República, año II, núm. 2, 2008, Montevideo.

"Formas de regulación en el mercado vitivinícola (Mendoza, primera mitad del siglo Xx)", Segundas Jornadas de la Historia de la Industria y los Servicios, Buenos Aires, Universidad de Buenos Aires, 2009.

"Estado, empresas y regulación. La experiencia de las entidades reguladoras del mercado vitivinícola de Mendoza (Argentina, 1914-1943)", Revista de Historia Industrial, Universidad de Barcelona, año XXI, núm. 49, 2012, España. 
"La intervención del Estado en la industria vitivinícola. El caso de Bodegas y Viñedos Giol (Mendoza 1954-1974)”, tesis doctoral, Buenos Aires, Argentina, 2013.

y Virginia Mellado, "La crisis de la vitivinicultura en los años 30. Alejandro Bunge y sus diagnósticos sobre las políticas económicas de regulación”, $X X$ Jornadas de Historia Económica, Mar del Plata, Universidad de Mar del Plata, 2006.

Olivera, Gabriela, Cooperativismo agrario: instituciones, políticas públicas y procesos históricos, Córdoba, Ferreyra, 2006.

Ospital, Silvia Ma., "Empresarios, dimensión étnica y agroindustrias. El caso del Centro Vitivinícola Nacional (1905-1930)", Ciclos en la Historia, la Economía y la Sociedad, Universidad de Buenos Aires, año 5, vol. 5, núm. 8, primer semestre de 1995, Buenos Aires, pp. 151-166.

"Los intereses comerciales de la vitivinicultura. Actuación del Centro Vitivinícola Argentino" en Guido Galafassi (comp.), El campo diverso. Enfoques y perspectivas de la Argentina agraria del siglo XX, Buenos Aires, Universidad Nacional de Quilmes, 2004.

"Políticas reguladoras en la vitivinicultura argentina. Crisis e intervención del Estado. 1930-1940”, III Congreso de Historia Vitivinícola Uruguaya y I Congreso de Historia Vitivinícola Regional, Montevideo, 2005.

"El caso de la vitivinicultura cuyana" en Noemí Girbal-Blacha, Silvia OSPITAL y ADRIÁN ZARRILLI, Las miradas diversas del pasado. Las economías agrarias del interior ante la crisis de 1930, Buenos Aires, Ediciones Nacionales, 2005.

"Modernización estatal y regulación económica en provincias vitivinicultoras, Mendoza, 1936-1946", Revista Mundo Agrario. Revista de Estudios Rurales, Universidad Nacional de La Plata, vol. 9, núm. 18, 2009, Argentina.

PANTALEÓn, Jorge, "El surgimiento de la nueva economía argentina: el caso Bunge" en Federico Neiburg y Mariano Plotkin, Intelectuales y expertos. La constitución del conocimiento social en la Argentina, Buenos Aires, Paidós, 2004.

Partido Peronista. Consejo Superior Ejecutivo, Manual del peronista, Buenos Aires, s. e., 1948.

Pérez Romagnoli, Eduardo, Patricia Barrio de Villanueva e Inés Sanjurjo, La región vitivinícola argentina. Transformaciones del territorio, la economía y la sociedad. 1870-1914, Buenos Aires, Universidad Nacional de Quilmes, 2006.

Prieto, María y Susana Choren, “Trabajo y comportamientos familiares en una ciudad finisecular. Mendoza 1890-1900", XAMA, Centro Regional de Investigaciones Científicas y Tecnológicas-Unidad de Antropología, 1990, Mendoza.

"El trabajo familiar en el contexto rural de Mendoza a fines del siglo XIX", $X A M A$, Área de Ciencias Humanas del Centro Regional de Investigaciones Científicas y Tecnológicas-Unidad de Antropología, 1994, Mendoza.

RAMírez, Hernán, Corporaciones en el poder. Institutos económicos y acción política en Brasil y Argentina, Argentina, Lenguaje Claro/Instituto de Pesquisas e Investigações 
Sociais/Fundación de Investigaciones Económicas Latinoamericanas/Fundación Mediterránea, 2007.

Recopilación de leyes, decretos y disposiciones sobre la industria vitivinícola, Argentina, Ministerios de Agricultura de la Nación, 1930-1940.

Richard-Jorba, Rodolfo, "El mercado de trabajo rural en Mendoza, un panorama sobre su formación y funcionamiento entre la segunda mitad del siglo XIX y comienzos del xx", Población y Sociedad, Revista Regional de Estudios Sociales, Instituto Superior de Estudios Sociales, núms. 8-9, 2000-2001.

"El mercado de trabajo vitivinícola en la provincia de Mendoza y los nuevos actores: El contratista de viña: aproximación a un complejo sistema de empresarios y trabajadores, 1880-1910”, Revista Interdisciplinaria de Estudios Agrarios, Universidad de Buenos Aires, núm. 18, 2003, Buenos Aires.

“¿Echar raíces o hacer la América? Un panorama de la inmigración europea hacia la región vitivinícola argentina y algunos itinerarios económicos en la provincia de Mendoza, 1850-1914”, Amérique Latine Histoire et Mémoire. Les Cahiers ALHIM, Migrations en Argentine II, Université Paris 8, núm. 9, 2004.

"Cuando el pasado nos acompaña. La vitivinicultura capitalista en Mendoza y San Juan en clave histórica, 1870-2006” en Javier Balsa, Graciela MAteo y María Silvia Ospital (coords.), Pasado y presente en el agro argentino, Buenos Aires, Lumiere, 2008.

Rocchi, Fernando, “Cronos, Hermes y Clío en el Olimpo del mundo académico: historia y teoría económica, 1960-2005” en JoRge GELMAN (coord.), La historia económica argentina en la encrucijada, Buenos Aires, Prometeo/Asociación Argentina de Historia Económica, 2006.

Rofman, Alejandro y Patricia Collado, "El impacto de la crisis de los años 20012002 sobre el circuito agroindustrial vitivinícola y los agentes económicos que lo integran", Revista de Estudios Regionales y Mercado de Trabajo, Sistema de Información del Mercado Laboral, núm. 2, 2006.

Rougier, MARCElo, La política crediticia del Banco Industrial durante el primer peronismo, Buenos Aires, Universidad de Buenos Aires, 2001.

Estudios sobre la industria argentina, Buenos Aires, Lenguaje Claro, 2010.

SAlVATORE, RiCARDo D., "Control del trabajo y discriminación: el sistema contratista en Mendoza, Argentina 1880-1920”, Desarrollo Económico. Revista de Ciencias Sociales, Instituto de Desarrollo Económico y Social, vol. 26, núm. 102, julio-septiembre de 1986, Buenos Aires, pp. 229-253.

SchVArzer, Jorge, Empresarios del pasado. La unión industrial argentina, Buenos Aires, Centro de Investigaciones Sociales sobre el Estado y la Administración/Imago Mundi, Buenos Aires, 1991. y Victoria ITZCOVITZ, Organizaciones corporativas del empresariado argentino: ADEBA (Asociación de Bancos Argentinos), Buenos Aires, Centro de Investigaciones Sociales sobre el Estado y la Administración, 1986. 
Sidicaro, Ricardo, La Bolsa de Comercio de Buenos Aires y la representación de los intereses empresarios, Buenos Aires, Centro de Investigaciones Sociales sobre el Estado y la Administración, 1988.

Los tres peronismos. Estado y poder económico 1946-1955, 1973-1976, 1989-1999, Buenos Aires, Siglo XXI, 2002.

Stigler, George J., "The Theory of Economic Regulation”, Bell Journal of Economics and Management Science, vol. 2, núm. 1, primavera de 1971, pp. 3-21.

Stiglitz, Joseph, "Regulación y fallas", Revista de Economía Institucional, Universidad Externado de Colombia, vol. 12, núm. 23, segundo semestre de 2010, Colombia, pp. 13-28.

Williamson, Oliver E., The Economic Institutions of Capitalism, Firms, Markets, Relational Contracting, Nueva York, Free Press, 1985. 